\title{
Process performance and quality attributes of temperature and step-down relative humidity controlled hot air drying of Panax notoginseng roots
}

\author{
Dalong Jiang ${ }^{1,2}$, Congcong $\mathrm{Li}^{2,3 *}$, Sara Zielinska ${ }^{4}$, Yanhong $\mathrm{Liu}^{1}$, Zhenjiang Gao ${ }^{1}$, \\ Rongyan Wang ${ }^{1}$, Zhi'an Zheng ${ }^{1 *}$ \\ (1. College of Engineering, China Agricultural University, Beijing 100083, China; \\ 2. Hebei Agricultural University, Baoding 071001, Hebei, China; \\ 3. Hebei Key Laboratory of Agricultural Big Data, Baoding 071001, Hebei, China \\ 4. Faculty of Mechanical and Power Engineering, Wroclaw University of Science and Technology, 50-370 Wroclaw, Poland)
}

\begin{abstract}
The effects of temperature and step-down relative humidity controlled hot-air drying (THC-HAD) on the drying kinetics, energy efficiency and quality, i.e., rehydration ratio (RR), color parameters $\left(L^{*}, a^{*}, b^{*}\right)$, total color difference $\left(\Delta E^{*}\right)$, Panax notoginseng saponins (PNS) content, and ginsenosides content $\left(R_{1}, R_{g 1}, R_{e}, R_{d}, R_{b 1}\right)$ of Panax notoginseng roots were evaluated. The drying time was significantly affected by the drying temperature followed by the relative humidity (RH) of the drying air. Special combination of drying conditions, i.e., drying temperature of $50^{\circ} \mathrm{C}$, relative humidity of $40 \%$ for $3 \mathrm{~h}$ and then continuous dehumidification from $40 \%$ to $8 \%$ allowed to shorten the drying time by $25 \%$ compared to drying at the same temperature and continuous dehumidification. The longer was the drying time under constant high RH of drying air, the lower was the RR of dried samples. The step-down RH strategy contributed to the formation of a porous structure, enhancement of drying efficiency and quality improvement. Generally, the ginsenosides content increased with the increase in temperature, while no obvious trend was recorded for ginsenoside $R_{1}$. The contents of the ginsenoside $R_{1}, R_{g 1}, R_{b 1}$ and PNS decreased with the increase in the drying time under constant high RH. Taking into account the drying time, energy consumption and quality attributes, drying at the temperature of $50^{\circ} \mathrm{C}$, constant $\mathrm{RH}$ of $40 \%$ for $3 \mathrm{~h}$ and then step-down $\mathrm{RH}$ from $40 \%$ to $8 \%$ was proposed as the most favorable combination of drying conditions for dehydration of whole Panax notoginseng roots.
\end{abstract}

Keywords: Panax notoginseng (Burk.) F. H. Chen (Araliaceae) roots, step-down relative humidity, hot air drying, process performance, quality attribute

DOI: $10.25165 /$ j.ijabe.20211406.6198

Citation: Jiang D L, Li C C, Zielinska S, Liu Y H, Gao Z J, Wang R Y, et al. Process performance and quality attributes of temperature and step-down relative humidity controlled hot air drying of Panax notoginseng roots. Int $\mathrm{J}$ Agric \& Biol Eng, 2021; 14(6): 244-257.

\section{Introduction}

Panax notoginseng (Burk.) F. H. Chen (Araliaceae) roots, called Jinbuhuan in China, is a precious Chinese medicinal used to treat blood loss and anemia. It is widely distributed in southwestern China, Myanmar and Nepal ${ }^{[1]}$. Saponins include $R_{1}, R_{g 1}, R_{e}, R_{d}$ and $R_{b 1}$ as their main medicinal components and are often used for extraction for clinical trials ${ }^{[2]}$. The sum of $R_{1}, R_{g 1}, R_{e}, R_{d}$, and $R_{b 1}$

\section{Received date: 2020-10-03 Accepted date: 2021-08-05}

Biographies: Dalong Jiang, PhD candidate, research interest: intelligent drying equipment research and development, Email: 3473972630@qq.com; Sara Zielinska, Master candidate, research interest: mechanical engineering, material science, Email: 253780@student.pwr.edu.pl; Yanhong Liu, PhD, research interest: agricultural product processing and storage, Email: liuyanhong@cau.edu.cn; Zhenjiang Gao, $\mathrm{PhD}$, research interest: intelligent drying equipment research and development, Email: zjgao@cau.edu.cn; Rongyan Wang, $\mathrm{PhD}$ candidate, research interest: agricultural machinery research and development, Email: 1606764744@qq.com.

*Corresponding author: Zhi'an Zheng, PhD, Associate Professor, research interest: agricultural machinery research and development. College of Engineering, China Agricultural University, Beijing 100083, China. Tel: +86-10-62736883, Email: zhengza@cau.edu.cn; Congcong Li, PhD, Associate Professor, research interest: intelligent information detection and processing. College of Information Science and Technology, Hebei Agricultural University, Baoding 071001, Hebei, China. Tel: +86-15033233222, Email: hebaulcc@126.com. contents is equal to the content of PNS. PNS may lower the risk of arterial thrombosis, prevent myocardial ischemia-reperfusion injuries, enhance cerebral microcirculation, and protect nerve cells $^{[3,4]}$.

Fresh Panax notoginseng roots are difficult to store for a long time because of the high moisture content of them (over 65\%). Drying of Panax notoginseng roots may inhibit the activity of enzymes, facilitate the extraction of medicinal ingredients, reduce transportation costs and extend their shelf life $\mathrm{e}^{[5,6]}$. At present, the market mainly adopts two methods of natural drying and drying room to dry fresh Panax notoginseng roots ${ }^{[7]}$. Sun drying and convective hot air drying are widely used to preserve food products $^{[7]}$. Sun drying of Panax notoginseng roots takes 13-15 d, while hot air drying at the temperature range from $30^{\circ} \mathrm{C}$ to $50^{\circ} \mathrm{C}$ and an air velocity of $1.0 \mathrm{~m} / \mathrm{s}$ of whole ginseng root takes $70-190 \mathrm{~h}^{[8]}$. Hot air drying of American ginseng roots has a number of disadvantages such as long drying time, shrinkage, ginsenoside content degradation, and color deterioration ${ }^{[1,5,8]}$. The excessive time of exposure of the product to the drying conditions may generate a degradation of the quality due to the long exposure to high temperatures. In addition, the hardening of the surface of ginseng roots during drying restricts moisture movement ${ }^{[9]}$. This phenomenon has been observed during the drying of Panax notoginseng roots ${ }^{[8]}$. The special combination of drying conditions, i.e., temperature and relative humidity may allow to 
shorten the drying time and improve product quality ${ }^{[10,11]}$. An increase of drying temperature at constant air humidity may reduce the drying time of the Panax notoginsengroots ${ }^{[8]}$. However, increasing the air temperature to a high level, e.g., $70^{\circ} \mathrm{C}$, may result in the reduction of total ginsenosides content, color deterioration, or case-hardening of roots ${ }^{[12,13]}$. Not only higher temperature but also higher air velocity and lower relative humidity (RH) may enhance more rapid rates of drying resulting in high convective heat and mass transfer rates at the product surface and then surface hardening ${ }^{[12]}$. Hot air impingement drying (drying air temperature of $45^{\circ} \mathrm{C}$, air velocity of $6 \mathrm{~m} / \mathrm{s}$ ) of American ginseng slices (thickness of $2 \mathrm{~mm}$ ) allowed to significantly shorten the drying time and well preserve ginsenosides ${ }^{[9]}$.

In order to solve the problem of case hardening and quality loss, a strategy of drying temperature and RH control is essential. In the step-down RH hot air drying, high RH air at a constant temperature is applied for a certain period of time in the initial drying stage to increase sample temperature and enhance internal moisture transfer. Then, the RH of the drying air is reduced to a fixed value at the same drying temperature to accelerate material surface moisture evaporation ${ }^{[14]}$. The step-down RH drying technology has been used for drying different fruit products, such as apricot halves, yam slices, carrot slabs ${ }^{[14-16]}$. It resulted in improved efficiency of drying and high quality attributes including color, and heat sensitive components ${ }^{[14-16]}$. The drying air of low temperature and high $\mathrm{RH}$ may have the same enthalpy as that at higher drying temperature and lower $\mathrm{RH}^{[16]}$. Keeping low temperatures and high $\mathrm{RH}$ at the initial stage of drying results in fast product temperature rise and more uniform distribution of temperature and moisture inside the material. This mitigates case-hardening caused by fast drying rate (DR) due to high drying temperature and low $\mathrm{RH}^{[14-16]}$. Therefore, it is boldly assumed that the moisture is always removed due to the vapor pressure difference between the environment and the material surface, and the drying intensity is severe under continuous dehumidification. On the contrary, although the moisture is slowly removed from the material surface, the drying intensity is weak, which may avoid the surface hardening of the material and help to speed up the drying process under step-down RH or constant $\mathrm{RH}$.

Relative humidity control is important for the selection of optimal drying parameters ensuring drying efficiency, and high quality of food products ${ }^{[14-16]}$. However, there is a general scarcity of published data on the effect of step-down RH control strategy on the drying characteristics of whole Panax notoginseng roots, and no one combined with the material center temperature, microstructure and texture characteristics to comprehensively analyze the influence mechanism of relative humidity in the drying process. Additionally, most of the published papers on the drying of Panax notoginseng roots are limited to their pharmacological and clinical aspects ${ }^{[4,8,17]}$. Therefore, the aims of this study were to evaluate the effects of temperature and humidity controlled hot-air drying (THC-HAD) i.e., constant drying temperature, constant relative humidity and step-down relative humidity on 1) the drying characteristics of whole Panax notoginseng roots; 2) quality attributes, such as color $\left(L^{*}, a^{*}, b^{*}, \Delta E^{*}\right)$, rehydration ratio, shrinkage, texture, ginsenosides contents $\left(R_{1}, R_{b 1}, R_{d}, R_{e}, R_{g 1}\right.$, PNS), and microstructure, as well as 3 ) specific energy consumption.

\section{Materials and methods}

\subsection{Material}

Freshly harvested three-year-old cultivated Panax notoginseng
(Burk.) F.H. Chen roots were obtained from Wenshan City, Yunnan Province, China. The initial moisture content of freshly harvested roots was $(2.19 \pm 0.10) \mathrm{g} / \mathrm{g}$ d.b. The initial moisture content of roots was checked using oven drying at the temperature of $105^{\circ} \mathrm{C}$ for $24 \mathrm{~h}$ according to the standard ${ }^{[18]}$. Panax notoginseng (Burk.) F. H. Chen roots of similar size and weight were selected for further experiments. The average radius, length, and weight of Panax notoginseng roots were $(4 \pm 1) \mathrm{cm}$, $(12 \pm 1) \mathrm{cm}$, and $(40 \pm 4) \mathrm{g}$, respectively. Panax notoginseng roots were washed with tap water, while an electric fan was used to remove the surface water. Fibrous root and rhizome were removed. Panax notoginseng roots were stored in a refrigerator at the temperature of $4{ }^{\circ} \mathrm{C}$ and relative humidity of $80 \%$ no longer than $3 \mathrm{~d}$ until the drying experiments. Before the drying experiment, the fresh Panaxnotoginseng roots were taken out from the refrigerator and left for about $4 \mathrm{~h}$ to reach the room temperature of $20^{\circ} \mathrm{C}$.

\subsection{Experimental equipment and design}

Temperature and humidity controlled hot-air drying (THC-HAD) drying experiments with step-down relative humidity (RH) strategy were performed in a laboratory-scale hot air drying equipment installed in the College of Engineering of China Agricultural University, Beijing, China. The schematic diagram (Figure 1) and details on the drying set-up have been previously reported in Reference [11].
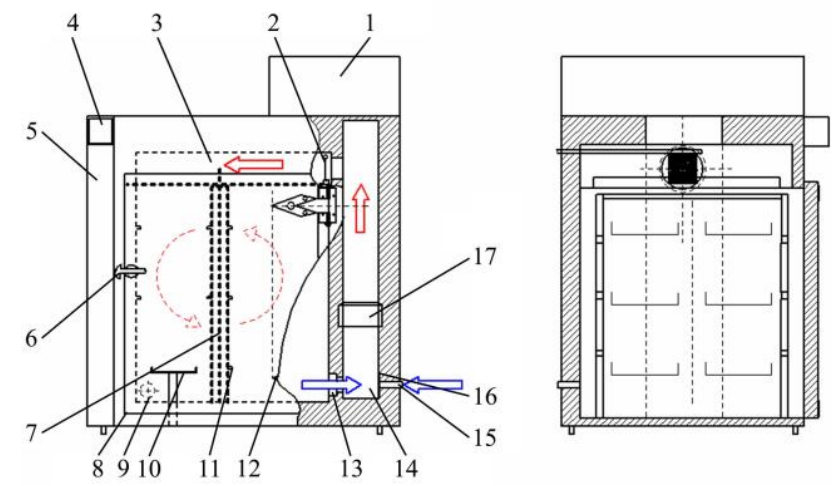

1. Humidification water tank 2. Wet curtain 3. Air bellow assembly 4. Human machine interface 5. Distribution box 6. Doorknob 7. Fan support 8. Drying chamber door 9 . Moisture removing centrifugal fan 10 . Weighing module 11. Tray support 12. Door hinge 13. Return air flue 14. Electric heating assembly 15 . Inlet air pipe 16 . Iron ore net 17 . Axial flow fan Note: Arrows represent the direction of air flow.

Figure 1 Schematic diagram of convective hot air dryer

Single-factor experiments were designed to evaluate the effects of constant drying temperature $\left(40^{\circ} \mathrm{C}, 50^{\circ} \mathrm{C}, 60^{\circ} \mathrm{C}\right.$, and $\left.70^{\circ} \mathrm{C}\right)$, constant relative humidity of drying air $(20 \%, 30 \%, 40 \%$, and $50 \%)$, as well as step-down relative humidity of drying air (constant $\mathrm{RH}$ of $40 \%$ for $0,1,3,5$ and $7 \mathrm{~h}$; Step-down relative humidity from $40 \%$ to $8 \%$ until the end of drying) on the drying characteristics and quality of Panax notoginseng roots. The detailed experimental arrangement is listed in Table 1. The hot air velocity was kept constant at $0.3 \mathrm{~m} / \mathrm{s}$ during drying. A single layer of Panax notoginseng roots (about $480 \mathrm{~g}$ ) was spread on a stainless steel wire mesh and placed in the drying chamber. The weight loss of samples was monitored by an automatic weighing system (Beijing Kang Sen Technology Co., China) with an accuracy of $\pm 0.01 \mathrm{~g}$. The mass of the sample was recorded every $60 \mathrm{~min}$ in the first $10 \mathrm{~h}$ and every $180 \mathrm{~min}$ until the end of drying ( $<0.15$ d.b.). After drying, samples were cooled down for $30 \mathrm{~min}$ packed in low-density polyethylene (LDPE) bags and sealed. All 
the experiments were done in triplicate. The average value of moisture content was used to calculate the drying curves.

Table 1 Experimental design for temperature and humidity controlled hot-air drying (THC-HAD) of Panaxnotoginseng roots

\begin{tabular}{|c|c|c|c|}
\hline No. & $\begin{array}{c}\text { Temperature } \\
/ /{ }^{\circ} \mathrm{C}\end{array}$ & Relative humidity $/ \%$ & $t_{T} / \mathrm{h}$ \\
\hline 1 & $\begin{array}{c}\text { Control (raw, } \\
\text { non-treated) }\end{array}$ & -- & -- \\
\hline 2 & 40 & Continuous dehumidification from $25 \%$ to $8 \%$ & 69.7 \\
\hline 3 & 50 & Continuous dehumidification from $25 \%$ to $8 \%$ & 55.0 \\
\hline 4 & 60 & Continuous dehumidification from $25 \%$ to $8 \%$ & 34.5 \\
\hline 5 & 70 & Continuous dehumidification from $25 \%$ to $8 \%$ & 98.0 \\
\hline 6 & 50 & $20 \%$ for $1 \mathrm{~h}$ and then continuous dehumidification to $8 \%$ & 55.0 \\
\hline 7 & 50 & $30 \%$ for $1 \mathrm{~h}$ and then continuous dehumidification to $8 \%$ & 49.0 \\
\hline 8 & 50 & $40 \%$ for $1 \mathrm{~h}$ and then continuous dehumidification to $8 \%$ & 44.5 \\
\hline 9 & 50 & $50 \%$ for $1 \mathrm{~h}$ and then continuous dehumidification to $8 \%$ & 52.8 \\
\hline 10 & 55 & $20 \%$ for $1 \mathrm{~h}$ and then continuous dehumidification to $8 \%$ & 53.0 \\
\hline 11 & 55 & $30 \%$ for $1 \mathrm{~h}$ and then continuous dehumidification to $8 \%$ & 49.0 \\
\hline 12 & 55 & $40 \%$ for $1 \mathrm{~h}$ and then continuous dehumidification to $8 \%$ & 43.0 \\
\hline 13 & 55 & $50 \%$ for $1 \mathrm{~h}$ and then continuous dehumidification to $8 \%$ & 52.0 \\
\hline 14 & 50 & $40 \%$ for $3 \mathrm{~h}$ and then continuous dehumidification to $8 \%$ & 40.5 \\
\hline 15 & 50 & $40 \%$ for $5 \mathrm{~h}$ and then continuous dehumidification to $8 \%$ & 52.2 \\
\hline 16 & 50 & $40 \%$ for $7 \mathrm{~h}$ and then continuous dehumidification to $8 \%$ & 61.2 \\
\hline
\end{tabular}

\subsection{Determination of drying characteristics of Panax} notoginseng roots

The moisture ratio (MR) of the Panax notoginseng roots during drying was calculated using the following equation ${ }^{[18]}$ :

$$
M R=\frac{M_{t}-M_{e}}{M_{0}-M_{e}}
$$

where, $M_{t}$ indicates the moisture content at a particular drying time $t$, $\mathrm{g} \cdot \mathrm{H}_{2} \mathrm{O} / \mathrm{g}$ d.b.; $M_{0}$ indicates the initial moisture content, $\mathrm{g} \cdot \mathrm{H}_{2} \mathrm{O} / \mathrm{g}$ d.b.; $M_{\mathrm{e}}$ indicates the equilibrium moisture content, $\mathrm{g} \cdot \mathrm{H}_{2} \mathrm{O} / \mathrm{g}$ d.b.

When the equilibrium moisture content $M_{e}$ is relatively small compared to $M_{t}$ or $M_{0}$, Equation (1) can be written in a simplified form:

$$
M R=\frac{M_{t}}{M_{0}}
$$

The drying rate (DR) of the Panax notoginseng roots under various drying conditions was calculated according to the following equation:

$$
D R=\frac{M_{t 1}-M_{t 2}}{t_{2}-t_{1}}
$$

where, $M_{t 1}$ and $M_{t 2}$ indicate the moisture contents, $\mathrm{g} \cdot \mathrm{H}_{2} \mathrm{O} / \mathrm{g}$ d.b. of Panax notoginseng roots at time $t_{1}$ and $t_{2}$, respectively; $t_{1}$ and $t_{2}$ indicate drying times, $\mathrm{h}$.

\subsection{Determination of color changes during drying of Panax} notoginseng roots

The color of cross-sections of fresh and dried Panax notoginseng roots was measured using a D65 colorimeter (WR-10, Shenzhen Weifu Photoelectric Technology Co., Ltd. China) with standard illuminant D65 and observer angle of $10^{\circ[19]}$. At least six measurements at different positions were made for each sample. Color was expressed in CIE $L^{*} a^{*} b^{*}$ scale, where parameter $L^{*}$ indicates white or black, parameter $a^{*}$ indicates red or green, and parameter $b^{*}$ indicates yellow or blue color. The index of total color change $\left(\Delta E^{*}\right)$ was calculated from the following equation $^{[18,19]}$ :

$$
\Delta E=\sqrt{\left(L^{*}-L_{0}^{*}\right)^{2}+\left(a^{*}-a_{0}^{*}\right)^{2}+\left(b^{*}-b_{0}^{*}\right)^{2}}
$$

where, $\Delta E^{*}$ indicates the total color change between fresh and dried roots; $L_{0}{ }^{*}, a_{0}{ }^{*}$, and $b_{0}{ }^{*}$ indicate the color parameters of fresh roots; $L^{*}, a^{*}$, and $b^{*}$ indicate the color parameters of dried samples.

\subsection{Determination of shrinkage of Panax notoginseng roots} during drying

The liquid displacement method was applied to evaluate the volume change of materials before and after drying ${ }^{[21]}$. All measurements were done in triplicate and the average value was used to present the results. Shrinkage $\left(S_{r}\right)$ was expressed as the ratio between the volume of the sample after and before drying.

$$
S_{r}=\frac{V_{0}-V_{f}}{V_{0}}
$$

where, $S_{r}$ indicates the ratio of volume before and after drying, \%; $V_{0}$ indicates the initial volume of the sample before drying, $\mathrm{cm}^{3} ; V_{f}$ indicates the volume of the sample after drying, $\mathrm{cm}^{3}$.

\subsection{Determination of rehydration ratio of dried Panax notoginseng roots}

The rehydration ratio (RR) was measured according to the methodology described by Zhao ${ }^{[10]}$ with some modifications. It was defined as the ratio of the mass of the rehydrated sample (g) to the mass of the dried sample before rehydration $(\mathrm{g})$ :

$$
R R=\frac{\text { Weight of sample after rehydration }}{\text { Weight of dry sample }}
$$

In order to measure RR of Panax notoginseng roots, the mass of about $15 \mathrm{~g}$ of dried sample was weighed and then immersed in a water bath filled with hot water for $24 \mathrm{~h}$. The temperature of water was set at $40^{\circ} \mathrm{C}$. Then, the roots were removed from water and blotted with paper towels to remove excess water from their surface. The rehydrated samples were weighed on an electric balance (Adventurer Pro AV4101, Ohaus, New Jersey, USA) with an accuracy of $\pm 0.001 \mathrm{~g}$. All experiments were carried out in triplicate and the average value was used to determine the rehydration ratio.

\subsection{Scanning electron microscope observations}

The microstructure of vertical cross-sections of the dehydrated roots was observed using a scanning electron microscope (SEM) (S-3500, Hitachi, Tokyo, Japan) at an accelerating voltage of $20 \mathrm{kV}$ according to the method described in References [8,9]. The samples were sputter-coated (SC7640, Quorum Technologies Ltd., Newhaven, UK) with an additional thin layer $(\sim 10 \mathrm{~nm})$ of gold $^{[19]}$. The images of representative areas were saved for further analysis. Images were observed at magnifications $\times 100$.

\subsection{Determination of ginsenosides contents}

The ginsenosides contents $R_{g 1}, R_{e}, R_{b 1}, R_{d}$, Panax notoginseng ginsenoside $R_{1}$ and Panax notoginseng saponins (PNS) were determined using high-performance liquid chromatography (HPLC) (Waters e2695, American) at $203 \mathrm{~nm}$ following the methodology described by Qu et al. ${ }^{[21]}$ with some modifications. The standards of ginsenoside $R_{1}, R_{g 1}, R_{e}, R_{b 1}$ and $R_{d}$ were purchased from the Chinese Medical and Biological Products Institute, Beijing, China. The dried samples under different drying conditions were crushed and then passed through a 40-mesh sieve with a $0.425 \mathrm{~mm}$ aperture. The mass of $400 \mathrm{mg}$ of the sample powder was accurately weighed on an electronic balance (AB135-S, Mettler Toledo, Greifensee, Switzerland) with an accuracy of $0.01 \mathrm{mg}$. The sample powder was placed in a $200 \mathrm{~mL}$ flask of a Soxhlet's extractor and $100 \mathrm{~mL}$ of $70 \%(\mathrm{v} / \mathrm{v})$ ethanol solution was added. The mixture was refluxed in a water-bath $\left(35^{\circ} \mathrm{C}\right)$ for $24 \mathrm{~h}$ to extract the ginsenosides and then the extract was evaporated for further analysis. A 
Prevail reverse-phase C8 column (Shimadzu, Tokyo, Japan) (150 $\mathrm{mm} \times 4.6 \mathrm{~mm}, 5 \mu \mathrm{m})$ was used to separate ginsenosides in a binary solvent consisting of acetonitrile $\left(\mathrm{CH}_{3} \mathrm{CN}\right.$, solvent $\left.\mathrm{A}\right)$ and distilled water (solvent $\mathrm{B}$ ) with a gradient elution: 0-25 min, 19\%-20\% A, $81 \%-80 \%$ B; $25-70$ min, $20 \%-40 \%$ A, $80 \%-60 \%$ B;
70-75 min, $40 \%-19 \%$ A, $60 \%-81 \%$ B. The column was then washed with $100 \%$ of solvent A for $15 \mathrm{~min}$ at a flow rate of $1.5 \mathrm{~mL} / \mathrm{min}$. All the above experiments were performed in triplicate and the average values were used. The absorbance units of the fresh and dried Panax notoginseng roots are shown in Figure 2.

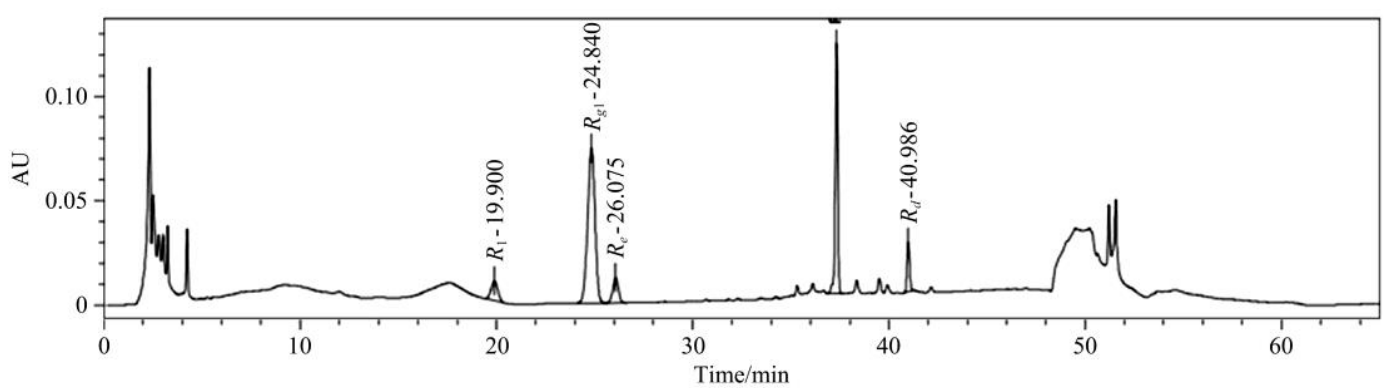

a. Raw Panax notoginseng root

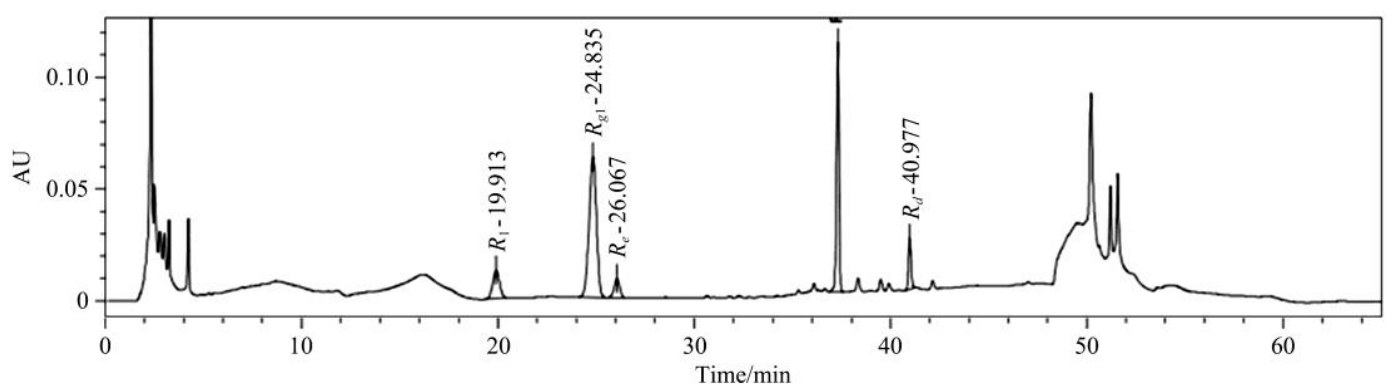

b. Panax notoginseng root dried by THC-HAD (T: $40^{\circ} \mathrm{C}, \mathrm{RH}$ : continuous dehumidification from $25 \%$ to $8 \%$ )

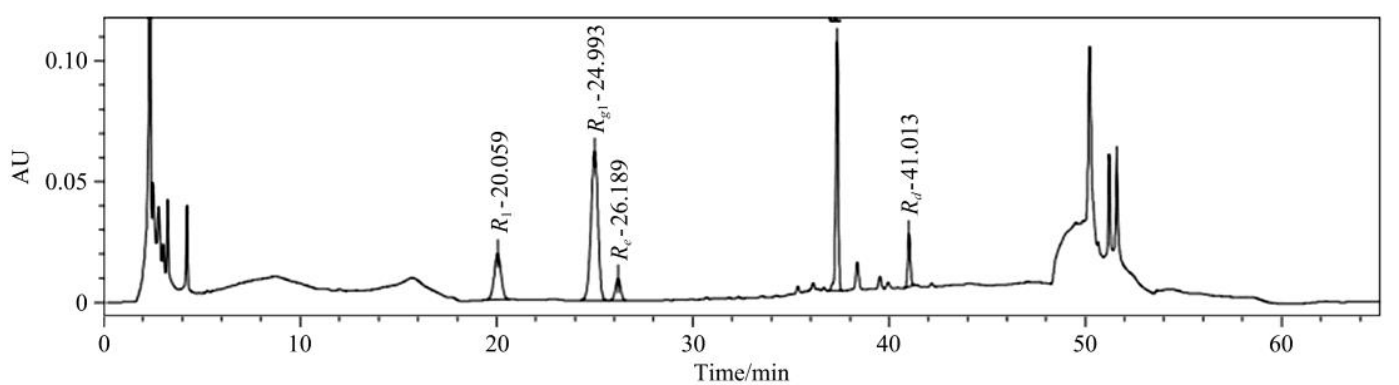

c. Panax notoginseng root dried by THC-HAD (T: $50^{\circ} \mathrm{C}$, RH: continuous dehumidification from $25 \%$ to $8 \%$ )

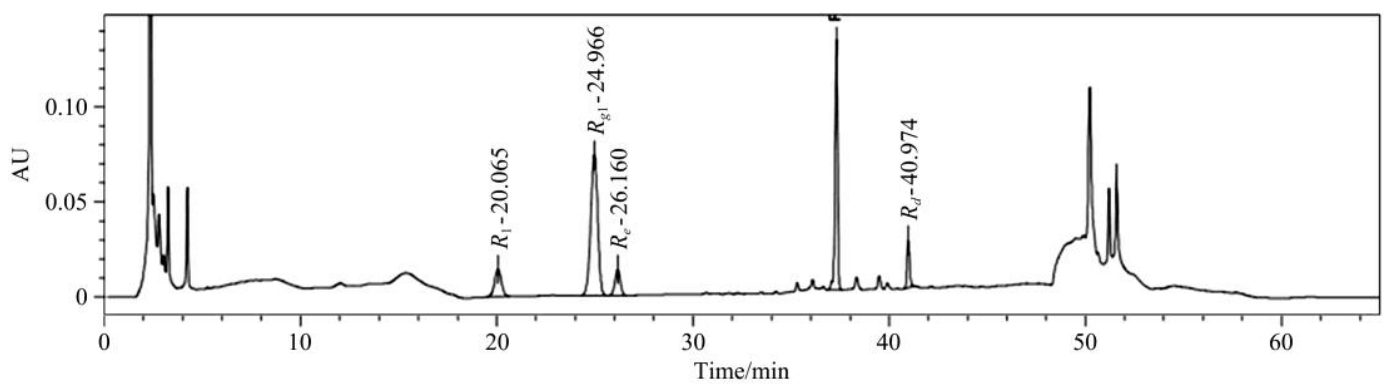

d. Panax notoginseng root dried by THC-HAD (T: $60^{\circ} \mathrm{C}$, RH: continuous dehumidification from $25 \%$ to $8 \%$ )

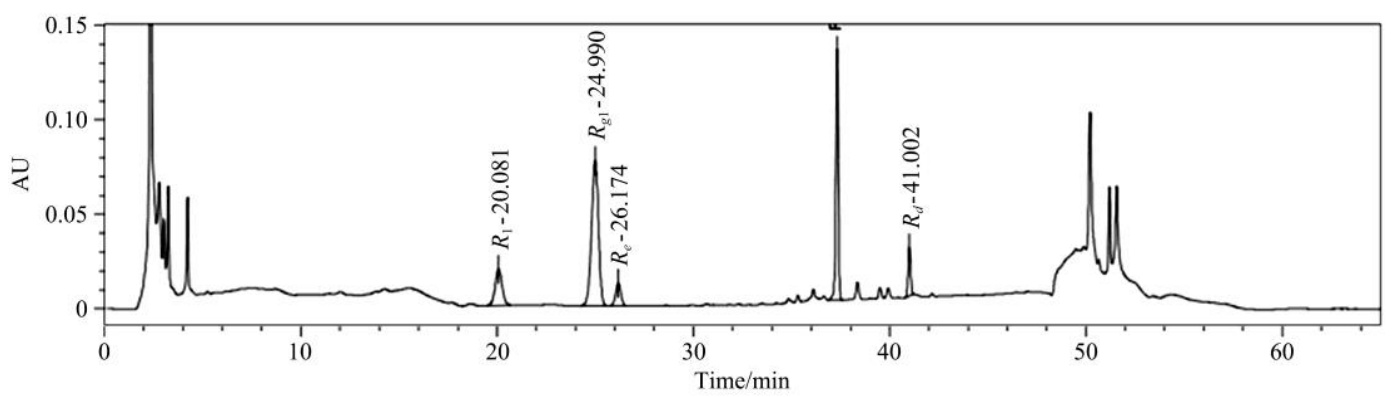

e. Panax notoginseng root dried by THC-HAD (T: $70^{\circ} \mathrm{C}$, RH: continuous dehumidification from $25 \%$ to $8 \%$ )

Note: AU: Absorbance unit.THC-HAD represents temperature and step-down relative humidity controlled hot-air drying; T represents temperature, ${ }^{\circ} \mathrm{C}$; RH: Relative humidity, \%, the same as below.

Figure 2 High-performance liquid chromatography (HPLC) chromatograms of the Panax notoginseng root 


\subsection{Determination of specific energy consumption}

In order to calculate the energy consumption of that drying equipment more accurately, the specific energy consumption $(\mathrm{Sec})$ was measured and recorded the corresponding time at the beginning and end of drying by single phase electronic meter (DTS7178, Shanghai Minrong Electric Co., Ltd., China) under the maximum loading capacity of each equipment. The $\mathrm{Sec}$ value was calculated from the following equation ${ }^{[11]}$ :

$$
\operatorname{Sec}=\frac{\Delta W}{G\left(M_{0}-M_{e}\right)}
$$

where, $\Delta W$ indicates the total energy consumption during drying, $\mathrm{kW} \cdot \mathrm{h} ; G$ indicates the absolute dry mass weigh of the drying material, $\mathrm{kg}$; Sec indicates the specific energy consumption, $\mathrm{kW} \cdot \mathrm{h} / \mathrm{kg} ; M_{0}$ and $M_{i}$ indicate the initial and final moisture content of the material, respectively.

\subsection{Measurement of material temperature}

A Pt100 temperature sensor (Beijing Kunlun-Zhongda Sensor Tech Co., Ltd., China, precision $\pm 0.2^{\circ} \mathrm{C}$ ) was used to monitor the temperature changes of the material during drying under different THC-HAD conditions. The sensor was inserted in the center of the dried particle. Heat accumulation (Ha) was calculated from the following equation ${ }^{[23]}$ :

$$
\mathrm{Ha}=\int_{t_{0}}^{t_{i}} T_{i} \mathrm{~d} t
$$

where, Ha indicates the integral of the temperature of the material center and time, ${ }^{\circ} \mathrm{C} \cdot \mathrm{h} ; t_{0}$ indicates the beginning of drying, $\mathrm{h} ; t_{i}$ corresponds to time $I, \mathrm{~h} ; T_{i}$ indicates the temperature of the material center at the moment $i$ of the drying process, ${ }^{\circ} \mathrm{C}$.

\subsection{Determination of texture properties}

The preliminary experiment showed that the hardness values of Panax notoginseng roots measured by compression method and puncture method were affected by the skin and fiber of Panax notoginseng roots. Finally, the hardness of dried Panax notoginseng roots was determined by the shear method. HDP/BS warner probe matched with texture analyzer (TA.XTPLUS/50, Stable Micro System, UK) was selected, and the velocity of the probe was set to $2 \mathrm{~mm} / \mathrm{s}$ before testing, and the shear ratio was set to $10 \%$.

\subsection{Statistical analyses}

To determine the differences among samples dried under different drying conditions the data were analyzed by LSD multiple comparison test using SPSS software (Version 21.0, SPSS Inc., Chicago, IL, USA). The significance of differences was tested at the $5 \%$ probability level $(p<0.05)$. The correlations between parameters were analyzed using Pearson's correlation test.

\section{Results and discussion}

3.1 Effects of the drying conditions on the drying kinetics, material temperature and energy consumption of drying of Panax notoginseng roots

Changes in the moisture ratios of Panax notoginseng roots vs. drying time as well as drying times vs. drying conditions during drying under different drying conditions are shown in Figure 3. The drying kinetics obtained under various drying air temperatures $\left(40^{\circ} \mathrm{C}, 50^{\circ} \mathrm{C}, 60^{\circ} \mathrm{C}\right.$, and $\left.70^{\circ} \mathrm{C}\right)$, continuous dehumidification from $25 \%$ to $8 \%$ and an air velocity of $0.3 \mathrm{~m} / \mathrm{s}$ are shown in Figure $3 \mathrm{a}$. Both drying temperature and $\mathrm{RH}$ significantly influenced the drying kinetics of Panaxnotoginseng roots. Drying at the temperature of $40^{\circ} \mathrm{C}, 50^{\circ} \mathrm{C}, 60^{\circ} \mathrm{C}$, and $70^{\circ} \mathrm{C}$ took $69.7,55.0,34.5$, and $98.0 \mathrm{~h}$. Increasing the drying temperature from $40^{\circ} \mathrm{C}$ to $60^{\circ} \mathrm{C}$ resulted in a significant reduction of drying time, while drying of Panax notoginseng roots at the temperature of $70^{\circ} \mathrm{C}$ resulted in the longest drying time. The drying rate was high at the initial stage of drying and then decreased rapidly. For high drying rates, the surface dried out faster than the core of Panax notoginseng roots and a formation of a case-hardened layer could hinder moisture migration. The results are consistent with published data, who had found that food drying under high temperature conditions tends to form texture development and surface hardening ${ }^{[23]}$. There was no constant drying rate period and the entire drying process took place in the falling drying rate period. This indicates that moisture diffusion was the main control mechanism for moisture transfer throughout the drying process. The results are consistent with data reported for hawthorn, sour cherry, and sorghum drying, these drying rates were all falling drying processes ${ }^{[24-27]}$. Surprisingly, moisture ratio curves under the drying condition, such as $70^{\circ} \mathrm{C}$, continuous dehumidification, $50^{\circ} \mathrm{C}$, RH keeping $20 \%$ for $1 \mathrm{~h}$ and then continuous dehumidification, $55^{\circ} \mathrm{C}$, RH keeping $20 \%$ for $1 \mathrm{~h}$ and then continuous dehumidification are obvious inflection points, which confirms the fact that the material surface hardens and crusts ${ }^{[23]}$. Because these drying conditions have a common feature, that is, intense drying intensity in the early stage of drying, high drying temperature, or low relative humidity will lead to the rapid evaporation of water on the material surface and hardening crust.

Drying temperature significantly affected the changes in material temperature and heat accumulation (Figure 4a). The rapid increase in the material temperature was noted at the very beginning of drying under constant drying temperatures of $40^{\circ} \mathrm{C}$, $50^{\circ} \mathrm{C}, 60^{\circ} \mathrm{C}$ and $70^{\circ} \mathrm{C}$, and continuous dehumidification. Then, it slowed down gradually with the drying time (Figure 4a). The heat accumulation of THC-HAD was directly proportional to the drying time (Figure 4a). Similar observations were made for carrot slabs dried under the constant drying temperature at $60^{\circ} \mathrm{C}$, air velocity of $3.0 \mathrm{~m} / \mathrm{s}$ and relative humidity of $20 \%, 30 \%, 40 \%$, and $50 \%^{[16]}$. Figure 3 also showed that the drying time taken to reduce the moisture content to its desired value increased when the drying temperature was decreased from $40^{\circ} \mathrm{C}$ to $60^{\circ} \mathrm{C}$. The drying times were $69.7,55.0$ and $34.5 \mathrm{~h}$ for the samples dried at temperatures of $40^{\circ} \mathrm{C}, 50^{\circ} \mathrm{C}$ and $60^{\circ} \mathrm{C}$, respectively. The results confirmed that increasing the drying temperature could significantly reduce the drying time. Perversely, the drying temperature of $70^{\circ} \mathrm{C}$ consumed more $63.5 \mathrm{~h}$ than that of $60^{\circ} \mathrm{C}$. This corresponds to the result of crust hardening on the material surface mentioned in Section 3.1.

Specific energy consumption during drying of Panax notoginseng roots under different THC-HAD conditions is shown in Figure 5. The specific energy consumption decreased from 25.69 to $18.95 \mathrm{~kW} \cdot \mathrm{h} / \mathrm{kg}$ as the drying temperature increased from $40^{\circ} \mathrm{C}$ to $70^{\circ} \mathrm{C}$. Drying temperature significantly influenced specific energy consumption during drying of Panax notoginseng roots. High temperature drying consumed less energy than low temperature drying of Panax notoginseng roots. The result is consistent with published data, who had also found high temperature drying consumed less energy than low temperature drying of Panax notoginseng roots dried by pulsed vacuum drying ${ }^{[23]}$. Energy consumption was negatively correlated with the drying temperature and positively correlated with the drying time $(p<0.01)$. The energy consumption of relative humidity at $40 \%$ was significantly lower than that of $30 \%$, and slightly lower than that of $50 \%$ under the constant drying temperature at $50^{\circ} \mathrm{C}$. 
This is because the suitable high RH environment in the early stage of drying can accelerate the material temperature rise. Due to the pressure difference of water vapor becoming larger, the drying process of the material is promoted, and the drying time is

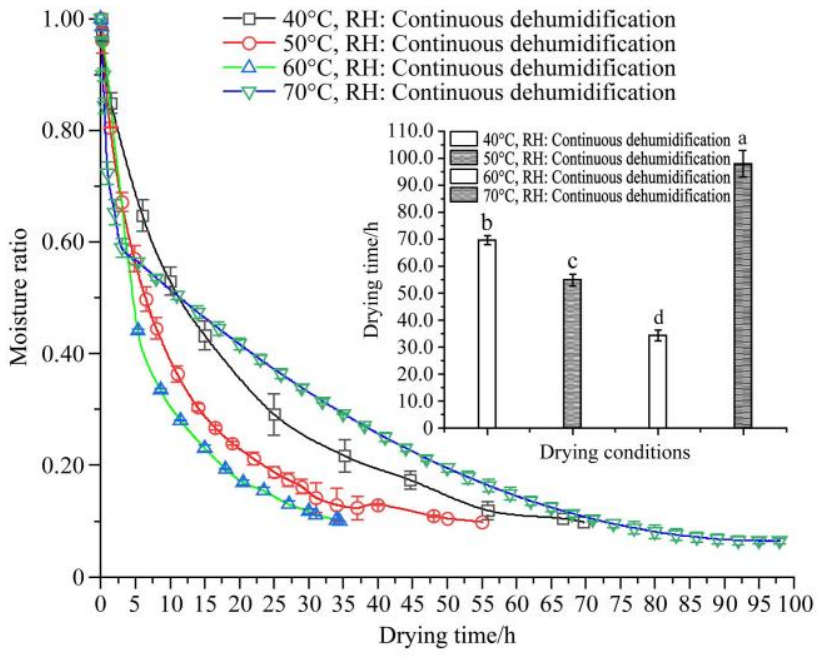

a. THC-HAD at constant drying temperatures of $40^{\circ} \mathrm{C}, 50^{\circ} \mathrm{C}, 60^{\circ} \mathrm{C}$ and $70^{\circ} \mathrm{C}$ and continuous dehumidification

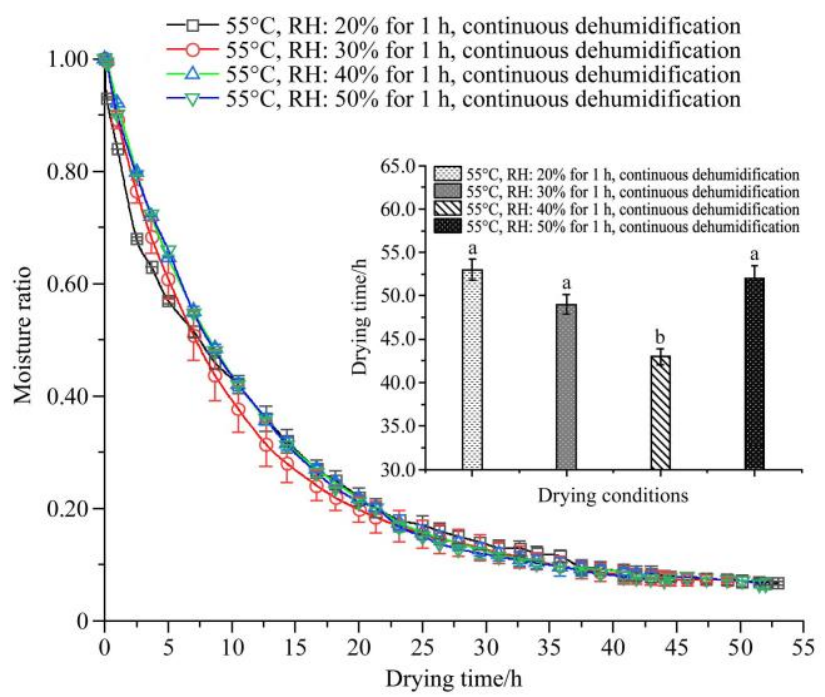

c. THC-HAD at the constant drying temperature of $55^{\circ} \mathrm{C}$, constant $\mathrm{RH}$ of

$20 \%, 30 \%, 40 \%$ and $50 \%$ for $1 \mathrm{~h}$ and then continuous dehumidification shortened to reduce the energy consumption when RH control strategy changed to continuous dehumidification. Compared with other relative humidity conditions of $20 \%, 30 \%$ and $50 \%$, the shortest drying time was $44.5 \mathrm{~h}$ at $40 \%$.

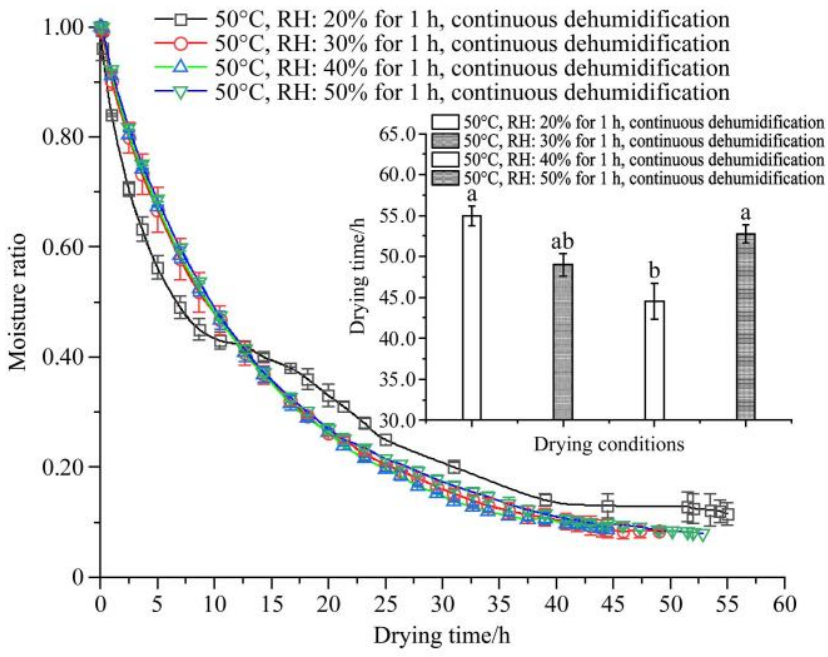

b. THC-HAD at the constant drying temperature of $50^{\circ} \mathrm{C}$, constant $\mathrm{RH}$ of $20 \%, 30 \%, 40 \%$ and $50 \%$ for $1 \mathrm{~h}$ and then continuous dehumidification

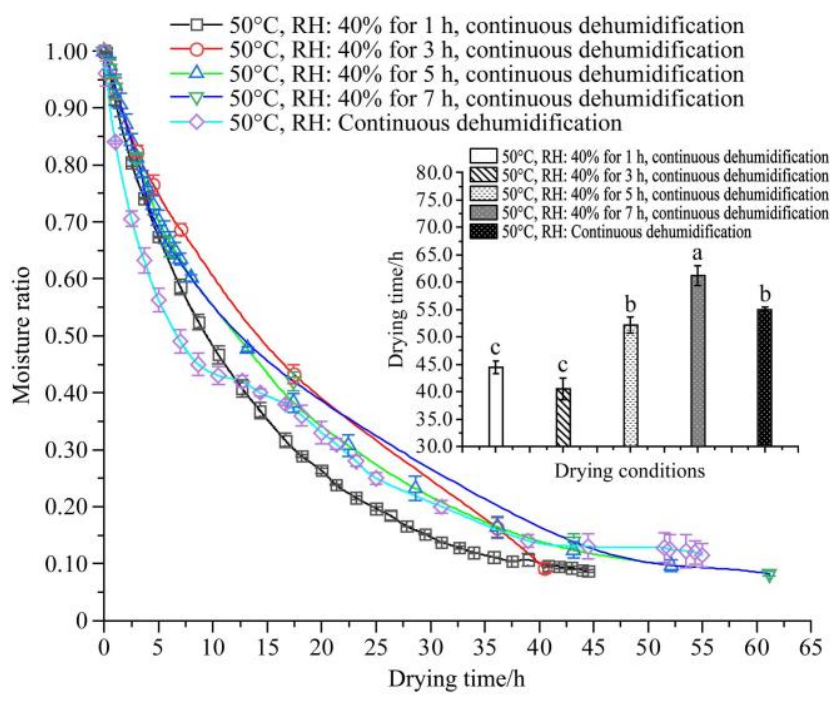

d. THC-HAD at the constant drying temperature of $50^{\circ} \mathrm{C}$, constant $\mathrm{RH}$ of $40 \%$ for $1,3,5,7 \mathrm{~h}$ and continuous dehumidification

Figure 3 Changes in the moisture ratios of Panax notoginseng roots vs. drying time as well as drying times vs. drying conditions during drying under different THC-HAD conditions

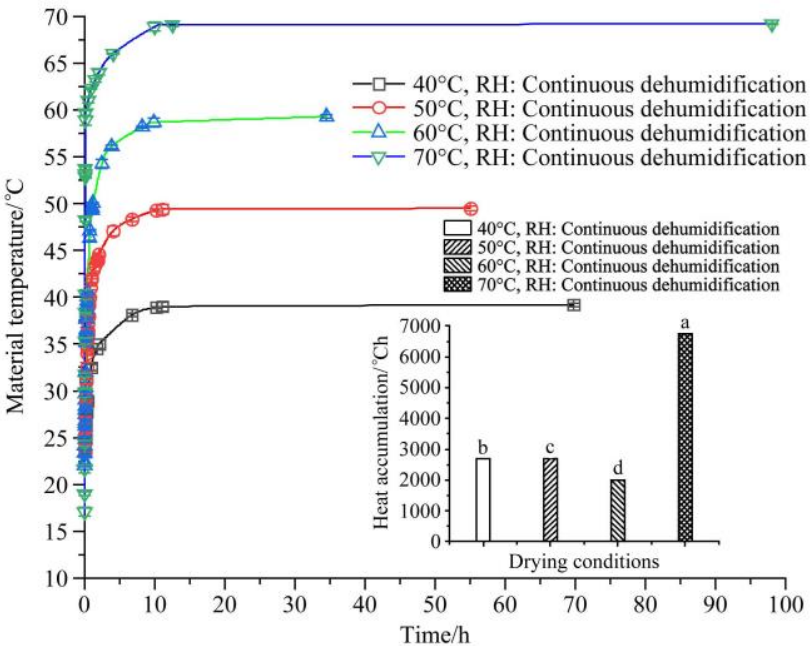

a. THC-HAD at constant drying temperatures of $40^{\circ} \mathrm{C}, 50^{\circ} \mathrm{C}, 60^{\circ} \mathrm{C}$ and $70^{\circ} \mathrm{C}$ and continuous dehumidification

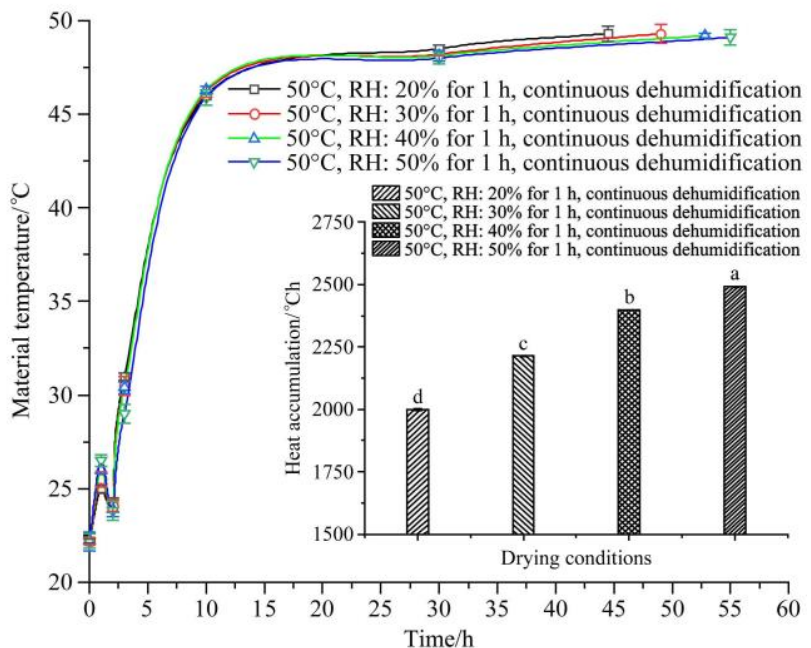

b. THC-HAD at the constant drying temperature of $50^{\circ} \mathrm{C}$, constant $\mathrm{RH}$ of $20 \%, 30 \%, 40 \%$ and $50 \%$ for $1 \mathrm{~h}$ and then continuous dehumidification 


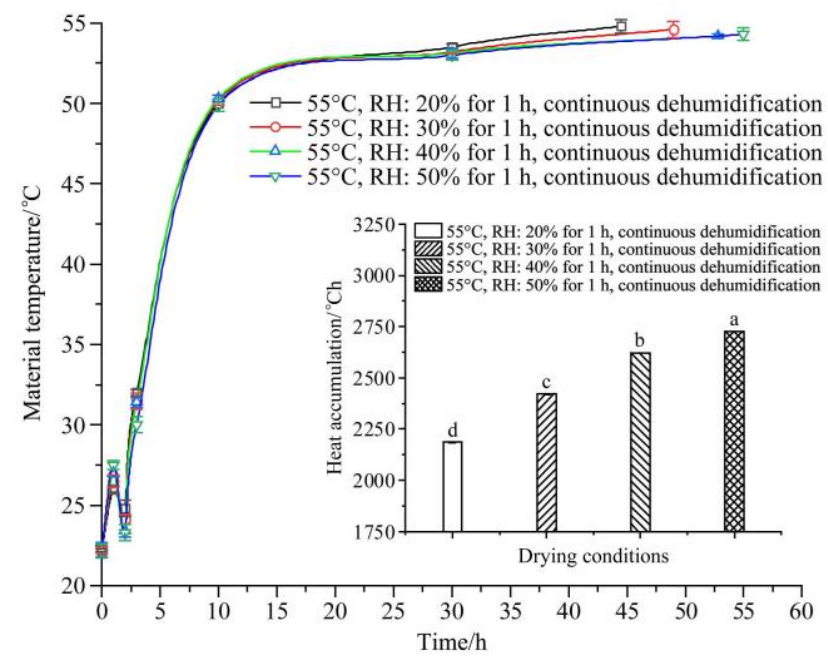

c. THC-HAD at the constant drying temperature of $55^{\circ} \mathrm{C}$, constant $\mathrm{RH}$ of $20 \%, 30 \%, 40 \%$ and $50 \%$ for $1 \mathrm{~h}$ and then continuous dehumidification

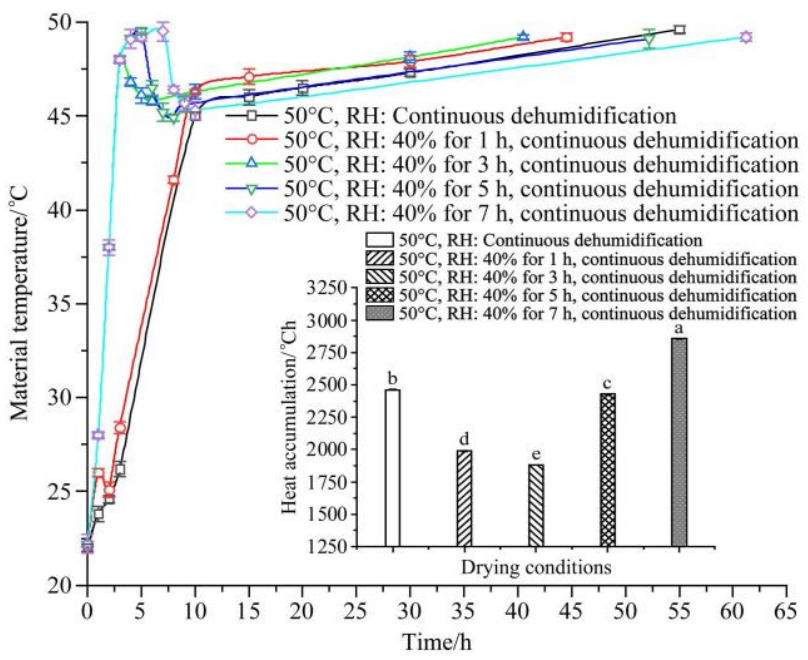

d. THC-HAD at the constant drying temperature of $50^{\circ} \mathrm{C}$, constant $\mathrm{RH}$ of $40 \%$ for $1,3,5,7 \mathrm{~h}$ and continuous dehumidification

Figure 4 Changes in the material temperature during drying of Panax notoginseng roots under different THC-HAD conditions

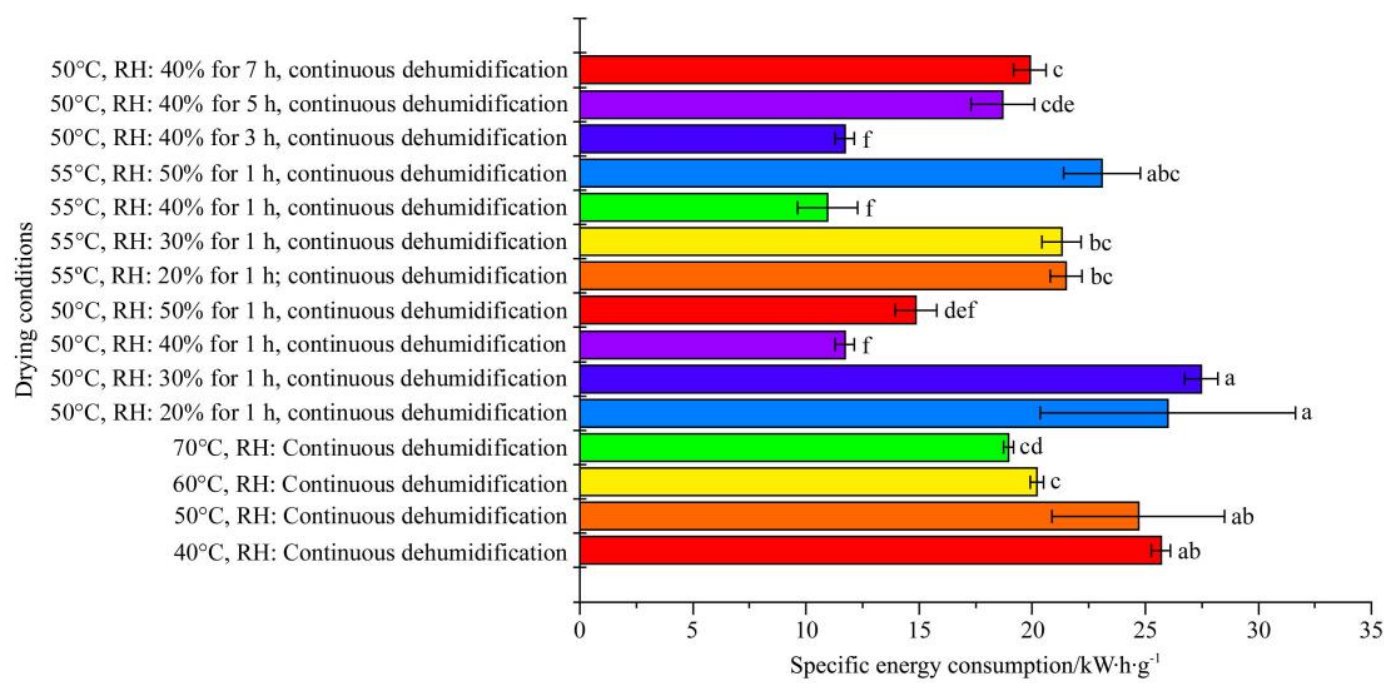

Note: a-f: The same letter in the same column means no significant difference $(p>0.05)$.

Figure 5 Specific energy consumption during drying of Panax notoginseng roots under different THC-HAD conditions

The changes in MR vs. drying time and DR vs. MR were obtained at the temperature of $50^{\circ} \mathrm{C}$ and $55^{\circ} \mathrm{C}$, air velocity of $0.3 \mathrm{~m} / \mathrm{s}$, constant RH of $20 \%, 30 \%, 40 \%$ and $50 \%$ for $1 \mathrm{~h}$ and then continuous dehumidification, are shown in Figures 3 and 6 , respectively. Drying at the temperature of $50^{\circ} \mathrm{C}$ and $\mathrm{RH}$ of $20 \%$, $30 \%, 40 \%$ and $50 \%$ maintained for $1 \mathrm{~h}$ and then continuous dehumidificationtook 55.0, 49.0, 44.5, and $52.8 \mathrm{~h}$, respectively. Drying at higher temperature, i.e., $55^{\circ} \mathrm{C}$ and $\mathrm{RH}$ of $20 \%, 30 \%, 40 \%$ and $50 \%$ maintained for $1 \mathrm{~h}$ and then continuous dehumidification took $53.0 \mathrm{~h}, 49.0 \mathrm{~h}, 43.0 \mathrm{~h}$, and $52.0 \mathrm{~h}$, respectively. An increase in drying temperature from $50^{\circ} \mathrm{C}$ to $55^{\circ} \mathrm{C}$ under the same $\mathrm{RH}$ and air velocity slightly shortened the drying time $(2.1 \%)$. The decreasing trend of RH values under the same drying temperature and air velocity did not result in a significant reduction of the drying time of Panax notoginseng roots. The RH of drying air of $40 \%$ was more beneficial for drying of Panax notoginseng roots than RH of $20 \%, 30 \%$ and $50 \%$. Relative humidity of $40 \%$ in the early stage of drying restrained water evaporation from the surface. However, the high value of enthalpy of the air of $40 \% \mathrm{RH}$ was the most beneficial for the temperature rise of the dried material and high rate of water evaporation in the later stages of drying ${ }^{[15]}$. Relative humidity of $50 \%$ increased water vapor pressure in the air and led to a significant decrease in the driving force for mass transfer, thus extending the drying time. Rapid DR dominated early in the drying at the temperature of $50^{\circ} \mathrm{C}$ or $55^{\circ} \mathrm{C}$ and $\mathrm{RH}$ of $20 \%$. It decreased significantly at the early stage of drying. Then, DR slowed down in the later stages of drying of Panax notoginseng root sand was found to be lower than that calculated for drying at the temperature of $50^{\circ} \mathrm{C}$ or $55^{\circ} \mathrm{C}$ and relative humidity of $30 \%, 40 \%$ and $50 \%$ (Figures $6 \mathrm{~b}$ and $6 \mathrm{c}$ ). The results are consistent with published data, which had also found the effect of drying yam slices at different $\mathrm{RH}^{[15]}$. The high difference between the water vapor pressure on the material surface and the air with low $\mathrm{RH}$ promoted the evaporation of water in the early drying stage. However, the surface of Panax notoginseng roots was susceptible to case hardening which could affect the subsequent drying ${ }^{[23]}$.

Relative humidity of the drying air significantly affected the changes in material temperature and heat accumulation (Figures $4 \mathrm{~b}$ and $4 \mathrm{c}$ ). Drying at the temperature of $50^{\circ} \mathrm{C}$ and $55^{\circ} \mathrm{C}$, constant $\mathrm{RH}$ of $20 \%, 30 \%, 40 \%$ and $50 \%$ for $1 \mathrm{~h}$ and then continuous dehumidification showed the same trend of changes in the material temperature. The results show that the material temperature was far from the air temperature and reached the values from $23^{\circ} \mathrm{C}$ to $28^{\circ} \mathrm{C}$ during $1 \mathrm{~h}$. Then, the material temperature decreased rapidly and increased gradually until the end of drying when the strategy of constant $\mathrm{RH}$ values of drying air was changed to the 
strategy of continuous dehumidification. Heat accumulation was related to the relative humidity of drying air. The higher was the relative humidity of drying air, the higher heat accumulation was noted (Figures $4 \mathrm{~b}$ and $4 \mathrm{c}$ ). A similar phenomenon was found during drying of American ginseng roots ${ }^{[11]}$. According to the moisture enthalpy diagram of air, the higher the RH was, the higher the wet-bulb temperature was, and the higher the enthalpy value was when the dry-bulb temperature was constant. As shown in

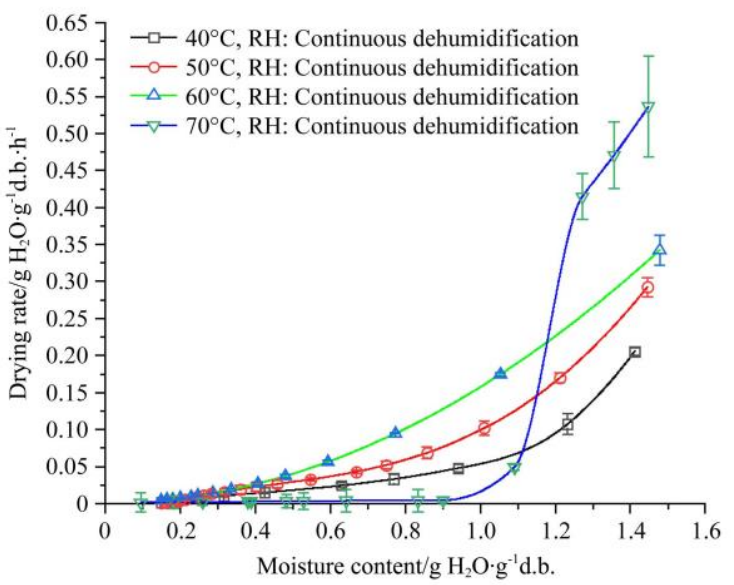

a. THC-HAD at constant drying temperatures of $40^{\circ} \mathrm{C}, 50^{\circ} \mathrm{C}$, $60^{\circ} \mathrm{C}$ and $70^{\circ} \mathrm{C}$ and continuous dehumidification

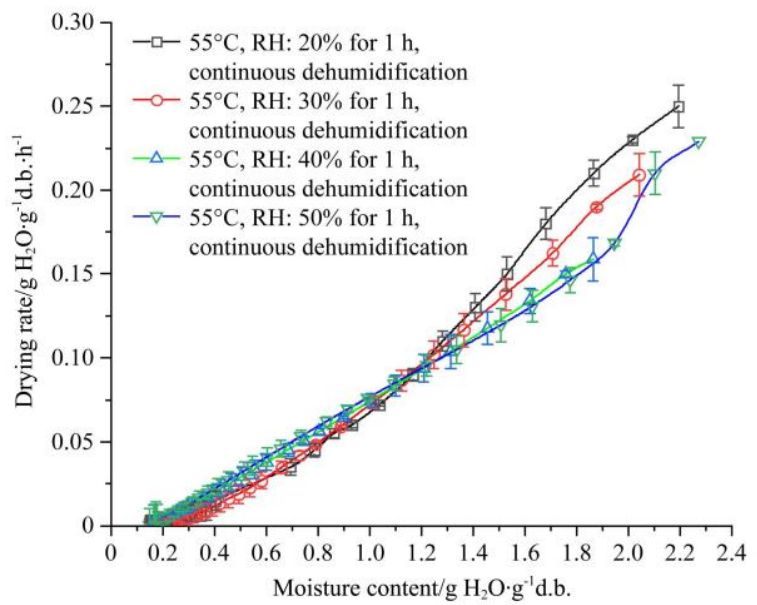

c. THC-HAD at the constant drying temperature of $55^{\circ} \mathrm{C}$, constant $\mathrm{RH}$ of $20 \%, 30 \%, 40 \%$ and $50 \%$ for $1 \mathrm{~h}$ and then continuous dehumidification
Figures $4 \mathrm{c}$ and $4 \mathrm{~d}$, the material temperature decreases rapidly at the time point when the relative humidity changes from high $\mathrm{RH}(20 \%$, $30 \%, 40 \%, 50 \%)$ to continuous dehumidification. This can be attributed to the difference between the water vapor on the material surface and the environment increases, which results in the rapid evaporation of the material surface water and the absorption of heat, which indirectly results in the material temperature decrease ${ }^{[11]}$.

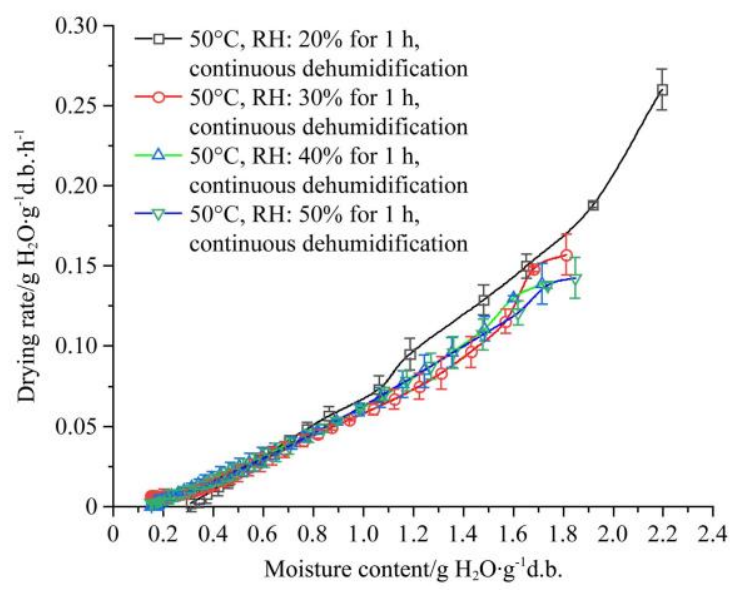

b. THC-HAD at the constant drying temperature of $50^{\circ} \mathrm{C}$, constant $\mathrm{RH}$ of $20 \%, 30 \%, 40 \%$ and $50 \%$ for $1 \mathrm{~h}$ and then continuous dehumidification

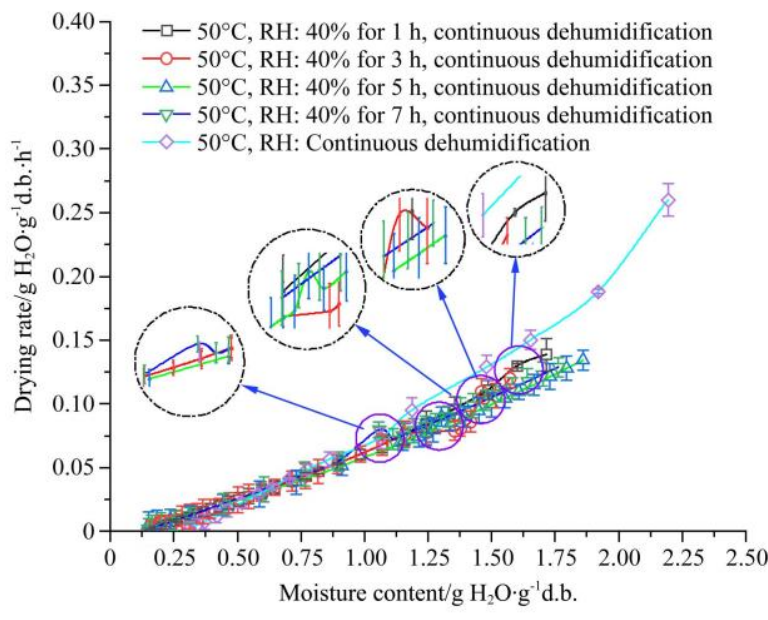

d. THC-HAD at the constant drying temperature of $50^{\circ} \mathrm{C}$, constant $\mathrm{RH}$ of $40 \%$ for $1,3,5,7 \mathrm{~h}$ and continuous dehumidification

Figure 6 Changes in the drying rates vs. moisture contents during drying of PanaxNotoginseng roots under different THC-HAD drying conditions

Increasing the $\mathrm{RH}$ of drying air from $20 \%$ to $40 \%$ under the constant drying temperature of $50^{\circ} \mathrm{C}$ and $55^{\circ} \mathrm{C}$ resulted in a significant reduction of energy consumption of drying of Panax notoginseng roots, while drying at the highest $\mathrm{RH}$ of drying air, i.e., $50 \%$, resulted in the highest energy consumption (Figure 5).

Drying at the temperature of $50^{\circ} \mathrm{C}$ and $\mathrm{RH}$ of $40 \%$ was maintained for $1,3,5,7 \mathrm{~h}$ and then continuous dehumidification from $40 \%$ to $8 \%$ took $44.5,40.5,52.2$, and $61.2 \mathrm{~h}$, respectively (Figure 6d). The drying of Panax notoginseng roots under step-down relative humidity strategy occurred in the falling rate drying process. It indicates that the drying rate crucially decreased due to the increase of internal moisture migration resistance. Step-down relative humidity strategy assuming RH of $40 \%$ maintained for $3 \mathrm{~h}$ and then continuous dehumidification from $40 \%$ to $8 \%$ resulted in the shortest drying time of Panax notoginseng roots. Compared to the drying at the same temperature and strategy assuming continuous dehumidification, it shortened the drying time by $26 \%$. Step-down relative humidity strategy assuming $\mathrm{RH}$ of $40 \%$ maintained for 1,3 and $5 \mathrm{~h}$ and then continuous dehumidification from $40 \%$ to $8 \%$ resulted in the shorter drying time compared to the drying at the same temperature and strategy assuming continuous dehumidification. The porous structure formed under the above-mentioned conditions could benefit moisture transfer and reduce the drying time of Panax notoginseng roots. Step-down relative humidity strategy assuming $\mathrm{RH}$ of $40 \%$ maintained for $7 \mathrm{~h}$ and then continuous dehumidification from $40 \%$ to $8 \%$ was unfavorable with regard to the drying time. Compared to the drying at the same temperature and strategy assuming continuous dehumidification, it prolonged the drying time by $11 \%$. The results show that proper selection of the step-down relative humidity strategy can significantly improve the efficiency of drying of Panax notoginseng roots. Due to high enthalpy, the high relative humidity of the air in the early stage of drying promoted rapid heating of materials. The high sample 
temperature provided an additional driving force for moisture diffusion from Panax notoginseng roots. The application of step-down relative humidity strategy assuming high $\mathrm{RH}$ of $40 \%$ maintained for 1,3 and $5 \mathrm{~h}$ seemed to over shadow the negative effect of high RH on the DR in the later stages of drying ${ }^{[27]}$. Additionally, a slight increase in DR for a short time occurred when RH changed from constant to step-down RH strategy (Figure 6d). This phenomenon could be explained by the fact that the vapor pressure difference increases with the decrease in RH of drying air ${ }^{[11,15]}$.

When the strategy assuming high $\mathrm{RH}$ of $40 \%$ changed to the strategy assuming continuous dehumidification, the material temperature decreased rapidly and then increased gradually until the end of drying due to moisture evaporation (Figure 6d). This is in agreement with the published report ${ }^{[11]}$. As shown above, material temperature close to the air temperature was not reached when the drying at the temperature of $50^{\circ} \mathrm{C}$, and $\mathrm{RH}$ of $40 \%$ for $1 \mathrm{~h}$. However, drying at the temperature of $50^{\circ} \mathrm{C}$, and strategy assuming constant RH of $40 \%$ for 3, 5 and $7 \mathrm{~h}$, allowed an obtained material temperature close to the air temperature.

The energy consumption of drying at the constant drying temperature of $50^{\circ} \mathrm{C}$ and $55^{\circ} \mathrm{C}, \mathrm{RH}$ of $40 \%$ for $3 \mathrm{~h}$ and then continuous dehumidification was significantly lower (from $12 \%$ to $29 \%$ ) than the energy consumption of drying at the same drying temperature, $\mathrm{RH}$ of $40 \%$ for 1,5 , and $7 \mathrm{~h}$ and then continuous dehumidification (Figure 5). Drying with step-down RH strategy (drying temperature of $50^{\circ} \mathrm{C}, \mathrm{RH}$ of $40 \%$ for $3 \mathrm{~h}$ and then continuous dehumidification) allowed to save about $40 \%$ energy compared to drying with strategy assuming continuous dehumidification from $25 \%$ to $8 \%$. Most probably, high RH of drying air in the initial drying stage increased material temperature and thus resulted in the surface hardening, reduction in drying time and energy consumption. The results are consistent with the data reported for convective drying of carrot cubes under a multistage relative humidity control strategy ${ }^{[16]}$.

\subsection{Rehydration ratio and microstructure of dried Panax notoginseng roots}

The drying temperature significantly influenced the RR of dried Panax notoginseng roots (Table 2). RR decreased from $(1.86 \pm 0.24)$ to $(1.24 \pm 0.15)$ with the increase in the drying temperature from $40^{\circ} \mathrm{C}$ to $70^{\circ} \mathrm{C}$ under continuous dehumidification and air flowrate of $0.3 \mathrm{~m} / \mathrm{s}$. Most probably, such a big difference in RR values of Panax notoginseng roots is related to the destruction of organizational structure that occurred during drying under different temperatures. The longer was the drying time the lower values of RR were noted. Drying at the temperature of $70^{\circ} \mathrm{C}$ was the longest, i.e., $98 \mathrm{~h}$, and it resulted in the lowest $\mathrm{RR}$ value (1.24 \pm 0.08$)$. The images of the microstructure of dried Panax notoginseng roots were included to explain the changes in the physicochemical properties of roots under different drying conditions. The microstructure of dried Panax notoginseng roots is shown in Figures $7 \mathrm{a}-7 \mathrm{k}$. The images show that the porous structure was formed during drying at the temperature of $40^{\circ} \mathrm{C}$ and $50^{\circ} \mathrm{C}$ and continuous dehumidification strategy (Figures $7 \mathrm{a}$ and $7 \mathrm{~b}$ ). A much denser structure was formed during drying at the temperature of $60^{\circ} \mathrm{C}$ and $70^{\circ} \mathrm{C}$ (Figures $7 \mathrm{c}$ and $7 \mathrm{~d}$ ). Due to extended drying time and rapid DR, the samples dried at the temperature of $60^{\circ} \mathrm{C}$ and $70^{\circ} \mathrm{C}$ displayed a collapsed structure and a dense gel layer on the surface of Panax notoginseng roots. The damage to the tissue structure dried at the temperature of $60^{\circ} \mathrm{C}$ and $70^{\circ} \mathrm{C}$ resulted in the limited water absorption. Since the microstructure of the products determines their macroscopic properties, the changes in microscopic level noted during drying of Panax notoginseng roots could influence their water penetration ability during rehydration ${ }^{[19,22,27]}$.

$\mathrm{RR}$ of roots dried under the constant drying temperature of $50^{\circ} \mathrm{C}$ or $55^{\circ} \mathrm{C}$, air flowrate of $0.3 \mathrm{~m} / \mathrm{s}$ and $\mathrm{RH}$ of $20 \%$ was significantly lower $(p \leq 0.05)$ than $\mathrm{RR}$ of roots dried at higher relative humidity of $30 \%, 40 \%$, and $50 \%$ (Table 2). The RR values of Panax notoginseng roots dried at the temperature of $50{ }^{\circ} \mathrm{C}$ and $55^{\circ} \mathrm{C}$ and $\mathrm{RH}$ of $20 \%, 30 \%, 40 \%$ and $50 \%$ were $(1.07 \pm 0.02)$, $(1.24 \pm 0.04),(1.28 \pm 0.03)$ and $(1.2 \pm 0.01)$ as well as $(1.02 \pm 0.03)$, $(1.19 \pm 0.05),(1.22 \pm 0.03)$ and $(1.18 \pm 0.01)$, respectively. At low $\mathrm{RH}$, surface hardening probably occurred in the early stage of drying of Panax notoginseng roots. The formation of a hard crust (case hardening) at the outside of the dried roots could act as a barrier to the moisture migration from the surrounding solution to the material during rehydration ${ }^{[27]}$. The results show that the relative humidity of the drying air significantly influenced the microstructure of the dried sample (Figures $7 \mathrm{e}, 7 \mathrm{f}, 7 \mathrm{~g}$, and $7 \mathrm{~h}$ ). The porous structure of Panax notoginseng roots dried at high $\mathrm{RH}$ of $40 \%$ and $50 \%$ is clearly presented in Figures $7 \mathrm{~g}$ and $7 \mathrm{~h}$. Most probably, the low evaporation pressure difference promoted the increase in overall material temperature and prevented crust formation ${ }^{[28]}$. However, the pores are not well seen in the case of roots dried at $\mathrm{RH}$ of $20 \%$ and $30 \%$ (Figures $7 \mathrm{e}$ and $7 \mathrm{f}$ ). Step-down RH strategy was more beneficial for porous structure formation than the strategy assuming continuous dehumidification from $25 \%$ to $8 \%$. The most favorable step-down strategy for porous structure formation without dense surface gel layer was strategy assuming high RH of $40 \%$ for $3 \mathrm{~h}$ (Figure7i).

$\mathrm{RR}$ of Panax notoginseng roots dried under the constant drying temperature of $50^{\circ} \mathrm{C}$ and step-down relative humidity strategy significantly decreased $(p \leq 0.05)$ from $(2.01 \pm 0.03)$ to $(1.55 \pm 0.05)$ with the increase in time to when constant high RH value was maintained (Table 2). An increase in time when a constant high RH value was maintained could lower the RR value of the dried Panax notoginseng roots. The values were even lower than those obtained for Panax notoginseng roots under the same temperature and continuous dehumidification strategy. This phenomenon might be due to the fact that the increase in time to maintain a constant high $\mathrm{RH}$ value could extend the drying time and highlight the negative effect of the temperature on the changes in the microstructure of dried roots ${ }^{[29]}$.

\subsection{Shrinkage of Panax notoginseng roots during drying}

The higher shrinkage of Panax notoginseng roots was observed when the drying air temperature increased from $40^{\circ} \mathrm{C}$ to $70^{\circ} \mathrm{C}$. However, the results of statistical analyses show that the influence of drying temperature on the shrinkage of Panax notoginseng roots was insignificant (Table 2). It was found that shrinkage of Panax notoginseng roots dried under strategy assuming step-down RH values were significantly lower than shrinkage of samples dried under strategy assuming continuous dehumidification. The results are consistent with the literature data ${ }^{[10]}$. High RH of the drying air in the early stage of drying resulted in the reduced moisture evaporation rate from the material surface, and thus reduced ability of the material to shrink and deform due to the removal of moisture. The shrinkage of mushrooms dried by hot air under the strategy assuming continuous dehumidification was larger than shrinkage of mushrooms dried under strategy assuming controlled step-down RH values ${ }^{[11]}$. The higher was the RH of drying air, the lower shrinkage ratio of dried 
Panax notoginseng roots was noted. Drying at the temperature of $50{ }^{\circ} \mathrm{C}, \mathrm{RH}$ of $20 \%, 30 \%, 40 \%$ and $50 \%$ for $1 \mathrm{~h}$ and then continuous dehumidification resulted in the volumetric shrinkage ratio of about (71 \pm 5$),(59 \pm 2),(15 \pm 4)$ and $(15 \pm 3)$, respectively. Drying at the temperature of $55^{\circ} \mathrm{C}, \mathrm{RH}$ of $20 \%, 30 \%, 40 \%$ and $50 \%$ for $1 \mathrm{~h}$ and then continuous dehumidification resulted in the volumetric shrinkage ratio of about $(73 \pm 1),(61 \pm 3),(17 \pm 2)$ and $(15 \pm 1)$, respectively. The higher RH of the drying air was applied in the early stage of drying, the lower the volumetric shrinkage ratio of dried Panax notoginseng roots was noted.

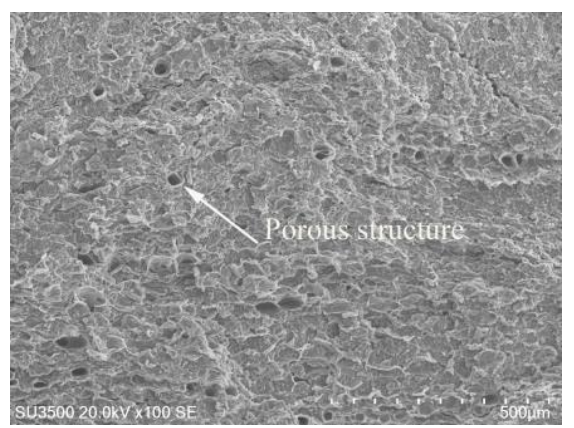

a. T: $40^{\circ} \mathrm{C}, \mathrm{RH}$ : continuous dehumidification

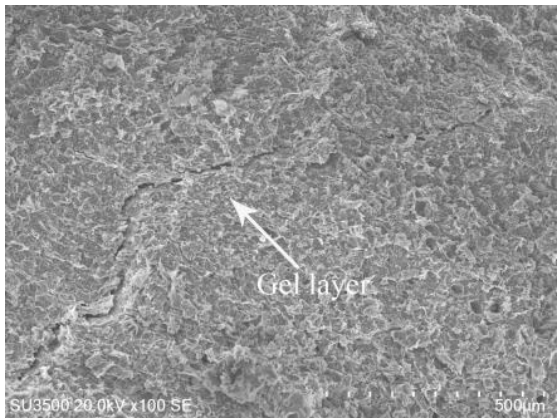

d. T: $70^{\circ} \mathrm{C}, \mathrm{RH}$ : continuous dehumidification

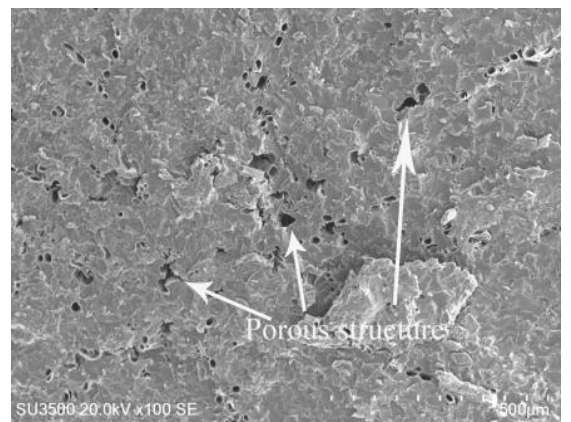

g. T: $50^{\circ} \mathrm{C}$; RH: $40 \%$ for $1 \mathrm{~h}$ and then continuous dehumidification

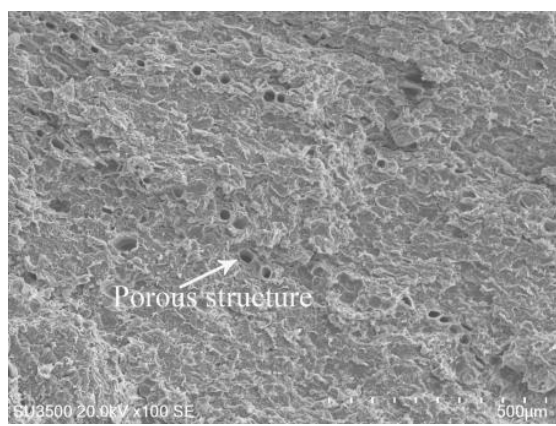

b. T: $50^{\circ} \mathrm{C}, \mathrm{RH}$ : continuous dehumidification

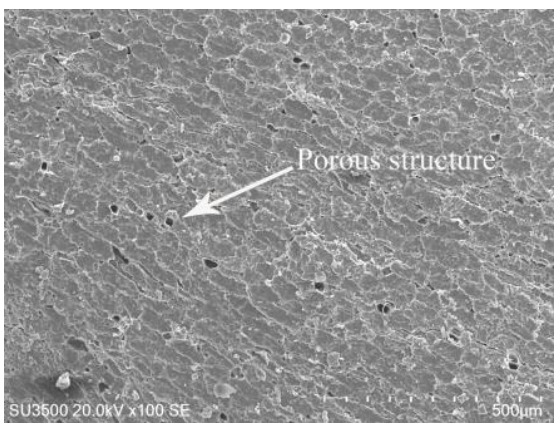

e. $\mathrm{T}: 50^{\circ} \mathrm{C}$; RH: $20 \%$ for $1 \mathrm{~h}$ and then continuous dehumidification

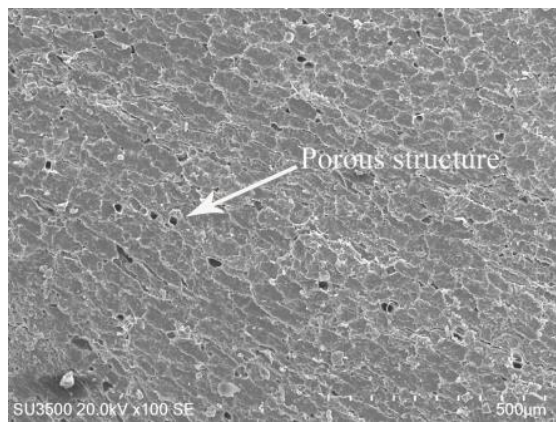

h. T: $50^{\circ} \mathrm{C}$; RH: $50 \%$ for $1 \mathrm{~h}$ and then continuous dehumidification

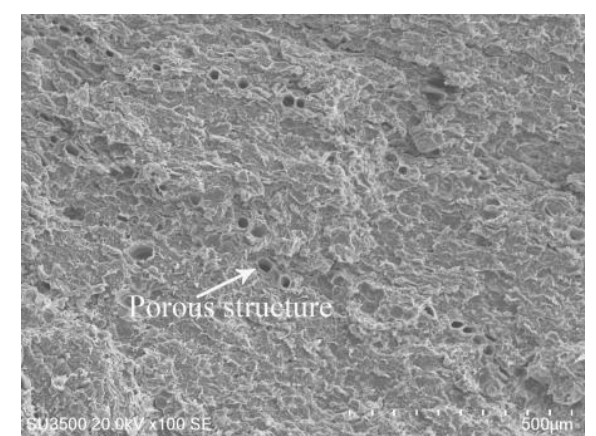

c. T: $60^{\circ} \mathrm{C}, \mathrm{RH}$ : continuous dehumidification

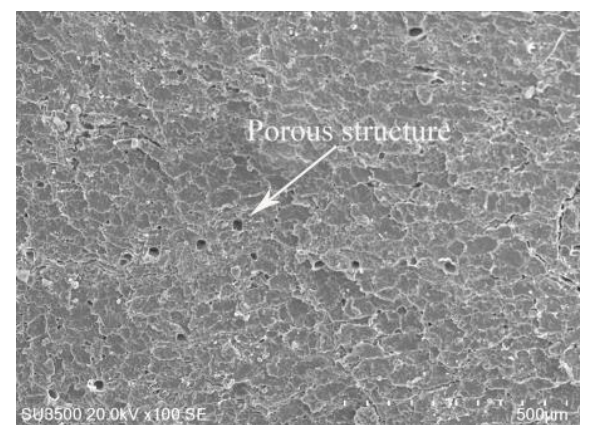

f. T: $50^{\circ} \mathrm{C}, \mathrm{RH}: 30 \%$ for $1 \mathrm{~h}$ and then continuous dehumidification

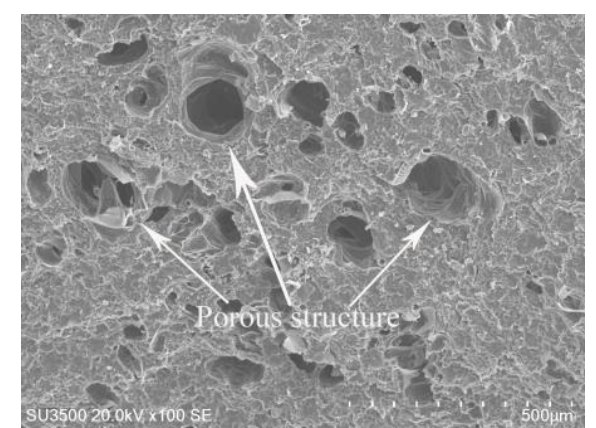

i. $\mathrm{T}: 50^{\circ} \mathrm{C}$; $\mathrm{RH}: 40 \%$ for $3 \mathrm{~h}$ and then continuous dehumidification

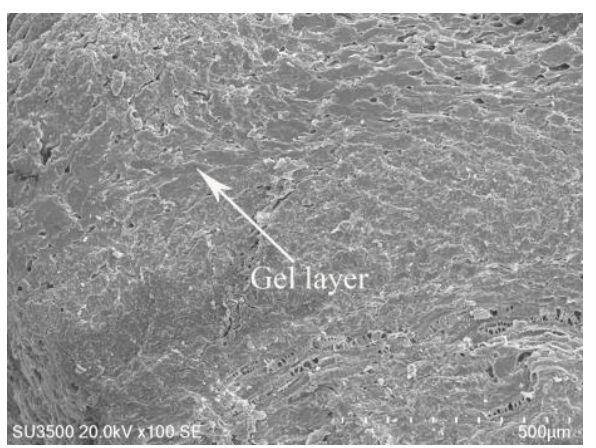

j. T: $50^{\circ} \mathrm{C}$; RH: $40 \%$ for $5 \mathrm{~h}$ and then continuous dehumidification

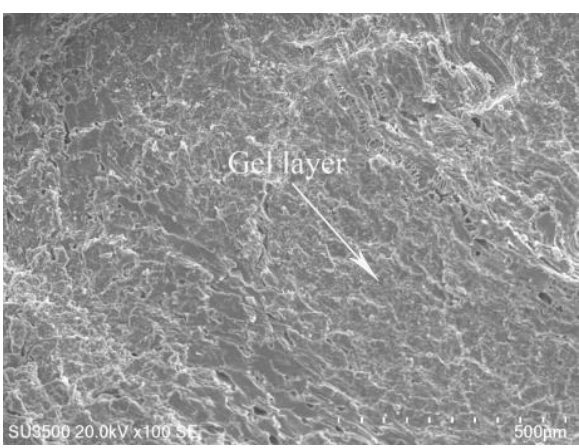

k. T: $50^{\circ} \mathrm{C}$; RH: $40 \%$ for $7 \mathrm{~h}$ and then continuous dehumidification

Figure 7 SEM images of Panaxnotoginseng roots dried under different THC-HAD conditions

Drying of Panax notoginseng roots at the temperature of $50^{\circ} \mathrm{C}$, $\mathrm{RH}$ of $40 \%$ and $50 \%$ for $1 \mathrm{~h}$ and then continuous dehumidification resulted in significantly smaller volumetric shrinkage ratio than drying at the same temperature, $\mathrm{RH}$ of 20 and $30 \%$ for $1 \mathrm{~h}$ and then continuous dehumidification (Table 2). High RH of the drying air in the early stage of drying was beneficial for uniform shrinkage of dried Panax notoginseng roots. Among others, it inhibited rapid moisture transfer from the center of the sample to its surface, and rapid evaporation of moisture from the material surface. It also allowed to avoid the creation of surface hardening and thus the 
more rapid surface moisture evaporation than the internal moisture migration $^{[31]}$. The application of strategy assuming high RH of the drying air during drying of shiitake mushrooms reduced surface hardening of the dried material. However, it resulted in longer drying time, larger shrinkage, more winkles on the sample surface, and lower RR compared to the strategy assuming continuous dehumidification $^{[31]}$. Similar results have been observed during drying of onion slices ${ }^{[32]}$

\subsection{Changes in ginsenosides and Panax notoginseng saponins contents of Panax notoginseng roots during dying}

Processing conditions should be considered important factors affecting the ginsenosides and Panax notoginseng saponins (PNS) contents of Panax notoginseng roots. Then, the changes in ginsenosides and Panax notoginseng saponins (PNS) contents of Panax notoginseng roots during drying were evaluated and the results are shown in Figure 8. Drying temperature significantly influenced the contents of ginsenosides and Panax notoginseng saponins (PNS) (Figure 8a). Unlike other ginsenosides content, the increase in the drying temperature from $40^{\circ} \mathrm{C}$ to $70^{\circ} \mathrm{C}$ under the strategy assuming continuous dehumidification resulted in a significant increase in ginsenoside $\mathrm{R}_{\mathrm{d}}$ content. In the case of ginsenosides $R_{g 1}, R_{e}$ and PNS, the most favorable drying temperature was $50^{\circ} \mathrm{C}$. In case of $R_{1}$ and $R_{b 1}$, the most favorable drying temperature was $60^{\circ} \mathrm{C}$ (Figure 8a). On the other hand, drying time was also important. The results can be explained by

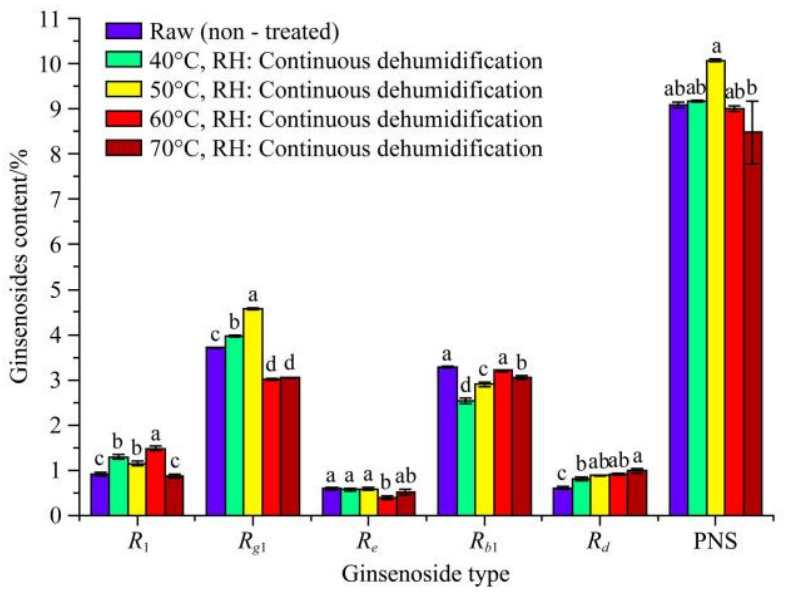

a. THC-HAD at constant drying temperatures of $40^{\circ} \mathrm{C}, 50^{\circ} \mathrm{C}, 60^{\circ} \mathrm{C}$ and $70^{\circ} \mathrm{C}$ and continuous dehumidification

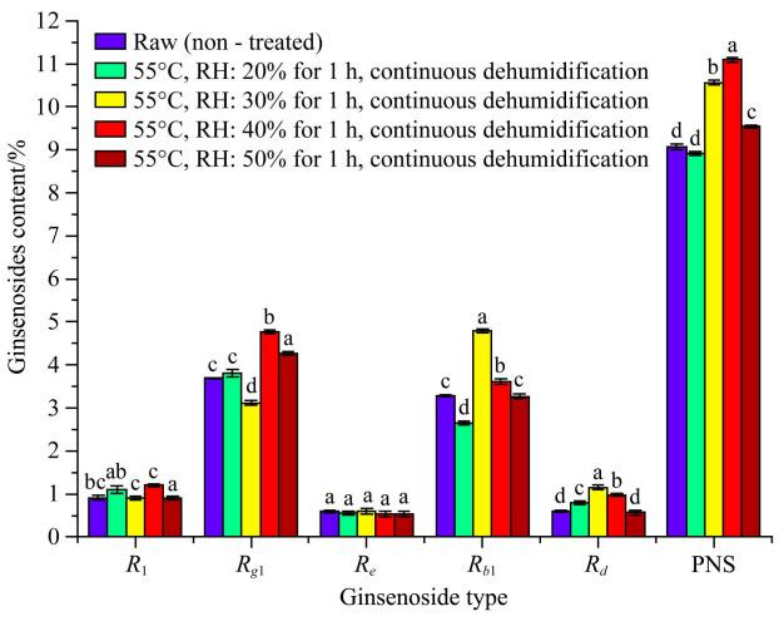

c. THC-HAD at the constant drying temperature of $55^{\circ} \mathrm{C}$, constant $\mathrm{RH}$ of $20 \%, 30 \%, 40 \%$ and $50 \%$ for $1 \mathrm{~h}$ and then continuous dehumidification the fact that ginsenosides are heat sensitive ingredients and they can be hydrolyzed during drying at low temperatures (e.g. $40^{\circ} \mathrm{C}$ $50^{\circ} \mathrm{C}$ ) for a long drying time or drying at high temperatures (e.g. $60^{\circ} \mathrm{C}-70^{\circ} \mathrm{C}$ ) for a short drying time $e^{[8]}$. Additionally, high temperature drying may help to convert $R_{b 1}$ into $R_{d}^{[33]}$. Drying at the temperature of $70^{\circ} \mathrm{C}$ resulted in the lower contents of $R_{e}$ than drying at the temperature of $60^{\circ} \mathrm{C}$ under the strategy assuming continuous dehumidification. However, the difference was insignificant. It can be explained by the fact that some unstable acidic ginsenosides (including the ginsenosides $m-R_{b 1}$, $m-R_{c}, m-R_{d}$, etc.) may be transformed into neutral ginsenosides (including the ginsenosides $R_{b 1}, R_{e}, R_{g 1}$, etc.) during thermal processing ${ }^{[34,35]}$. During processing, PH of Panax notoginseng extract changed from $(4.3 \pm 0.5)$ to $(6.4 \pm 0.8)$. The results also show that the contents of $R_{1}, R_{g 1}, R_{d}$ and PNS of Panax notoginseng roots dried at the temperature of $40^{\circ} \mathrm{C}$ or $50^{\circ} \mathrm{C}$ and the strategy assuming continuous dehumidification were significantly higher than that of fresh samples (Figure 8a). These results prove that the drying temperature had a significant influence on the conversion of ginsenosides and suggest that processing conditions should be carefully employed to enhance or retain the pharmaceutical effects of Panax notoginseng roots. It is consistent with published data, who was exploring the impact of different processing methods on the quality of American ginseng $^{[35]}$.

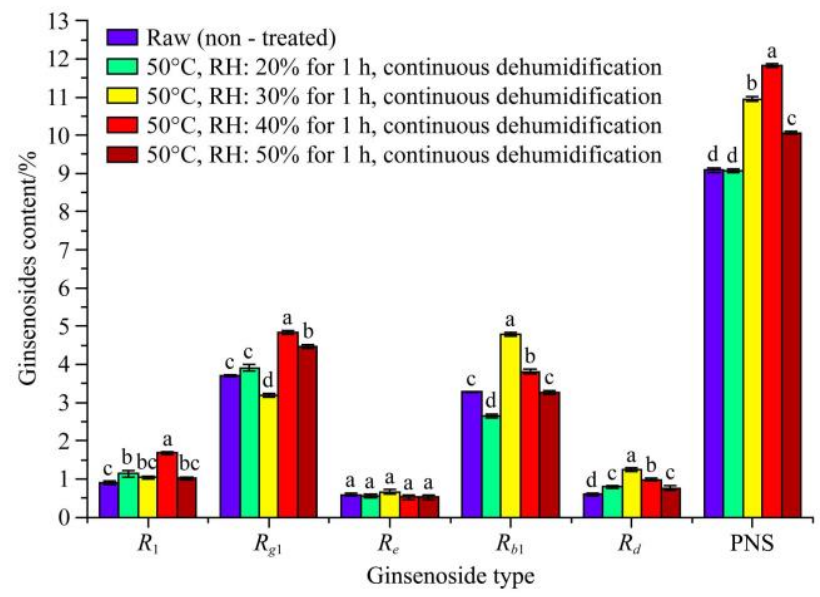

b. THC-HAD at the constant drying temperature of $50^{\circ} \mathrm{C}$, constant $\mathrm{RH}$ of $20 \%, 30 \%, 40 \%$ and $50 \%$ for $1 \mathrm{~h}$ and then continuous dehumidification

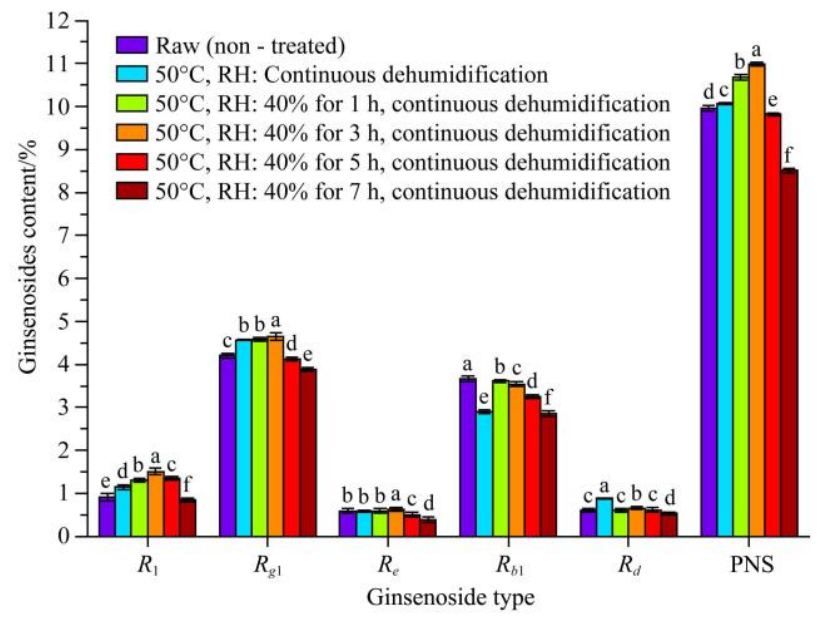

d. THC-HAD at the constant drying temperature of $50^{\circ} \mathrm{C}$, constant $\mathrm{RH}$ of $40 \%$ for $1,3,5,7 \mathrm{~h}$ and continuous dehumidification

Figure 8 Contents of $R_{1}, R_{g 1}, R_{e}, R_{d}, R_{b 1}$ ginsenosides and Panax notoginseng saponins of Panax notoginseng roots dried under different THC-HAD conditions 
Drying at the temperature of $50^{\circ} \mathrm{C}$ and $55^{\circ} \mathrm{Cand} \mathrm{RH}$ of $30 \%$ for $1 \mathrm{~h}$ resulted in the higher contents of $R_{e}, R_{b 1}$ and $R_{d}$ of Panax notoginseng roots than Panax notoginseng roots than drying at the temperature of $50^{\circ} \mathrm{C}$ and $55^{\circ} \mathrm{C}$ and $\mathrm{RH}$ of $20 \%, 40 \%$ and $50 \%$ (Figures $8 \mathrm{~b}$ and $8 \mathrm{c}$ ). Drying at the temperature of $50^{\circ} \mathrm{C}$ and $55^{\circ} \mathrm{C}$ and RH of $40 \%$ for $1 \mathrm{~h}$ resulted in the higher contents of $R_{1}, R_{g 1}$ and PNS of Panax notoginseng roots than Panax notoginseng roots than drying at the temperature of $50^{\circ} \mathrm{C}$ and $55^{\circ} \mathrm{Cand} \mathrm{RH}$ of $20 \%, 30 \%$ and $50 \%$ (Figures $8 \mathrm{~b}$ and $8 \mathrm{c}$ ).

Drying at the temperature of $50^{\circ} \mathrm{C}$, constant $\mathrm{RH}$ of $40 \%$ for $3 \mathrm{~h}$ and then continuous dehumidification resulted in significantly higher contents of ginsenoside $R_{1}, R_{g 1}, R_{d}$ and PNS than drying at the temperature of $50^{\circ} \mathrm{C}$, constant $\mathrm{RH}$ of $40 \%$ for 1,5 and $7 \mathrm{~h}$ and then continuous dehumidification.

The contents of the ginsenoside $R_{1}, R_{\mathrm{g} 1}, R_{\mathrm{b} 1}, R_{\mathrm{e}}$ and PNS of Panaxnotoginseng roots dried at the temperature of $50^{\circ} \mathrm{C}$ and step-down RH strategy (RH of $40 \%$ for 1 or $3 \mathrm{~h}$ and then continuous dehumidification) was higher than that found in Panax notoginseng roots dried at the same drying temperature and strategy assuming continuous dehumidification (Figure 8d). The results indicate that drying at high temperature and high $\mathrm{RH}$ for a long time promoted the hydrolysis of major ginsenosides. The mechanism of saponin transformations may be similar to the one observed during steaming of Panax notoginseng saponins ${ }^{[35]}$. Most probably, the C-20 glucosyl group of ginsenoside $R_{b 1}$ was hydrolyzed to yield ginsenoside $R_{d}$. The hydrolysis of the xylosyl residue attached to C-6 of notoginsenoside $R_{1}$ and the hydrolysis of the rhamnosyl residue at C-6 of ginsenoside $R_{e}$ formed ginsenoside $R_{g 1}$ during drying. Then, $R_{g 1}$ and $R_{d}$ were likely to be the parent compounds of newly formed saponins ${ }^{[35]}$. The correct selection of processing conditions may enhance or retain high ginsenosides and PNS contents and the pharmaceutical effects of Panax notoginseng roots. It can be clearly seen that some of the dried Panax notoginseng roots were characterized by the higher contents of some ginsenosides and PNS than the fresh roots.

\subsection{Color and texture changes of Panaxnotoginseng roots during drying}

The values of parameter $L^{*}$ of Panax notoginseng roots gradually decreased, while the values of parameter $a^{*}$ as well as the index of $\Delta E^{*}$ gradually increased with the increase in the drying temperature from $40^{\circ} \mathrm{C}$ to $70^{\circ} \mathrm{C}$. The results indicate that dried Panax notoginseng roots were darker and more red than the fresh samples. Most probably, it was related to the degradation of pigments or non-enzymatic Maillard browning ${ }^{[9]}$. The results are consistent with data reported for American ginseng ${ }^{[9-11]}$. The values of parameter $b^{*}$ initially increased and then decreased with the increase in the drying temperature from $40^{\circ} \mathrm{C}$ to $70^{\circ} \mathrm{C}$.

The trend of color changes of Panax notoginseng roots dried under the temperature of $50^{\circ} \mathrm{C}$ and $55^{\circ} \mathrm{C}$ and $\mathrm{RH}$ of $20 \%$ was similar to the one observed under the temperature of $50^{\circ} \mathrm{C}$ and $55^{\circ} \mathrm{C}$ and RH of $30 \%, 40 \%$ and $50 \%$. The lightness of Panax notoginseng roots firstly decreased, then increased, and finally rapidly decreased with the increase in $\mathrm{RH}$ values. In the case of redness of Panax notoginseng roots, it significantly decreased and then rapidly increased with the increase in $\mathrm{RH}$ of drying air. The opposite trend was observed in the case of yellowness of Panax notoginseng roots. Total color change $\left(\Delta E^{*}\right)$ firstly increased and then rapidly decreased with the increase in $\mathrm{RH}$ values. The $\mathrm{RH}$ values could affect the reflected light intensity of starch and then variability in the whiteness $\left(L^{*}\right)$ of dried roots. The increase in $\mathrm{RH}$ of drying air promoted the reactions between the amino acids and reducing sugars of Panax notoginseng roots and influenced the redness of roots ${ }^{[9]}$.

The values of $L^{*}$ parameter decreased, the values of $a^{*}$ parameter firstly increased and then decreased, while the values of $b^{*}$ parameter firstly decreased and then increased when drying of Panax notoginseng roots was conducted at the temperature of $50^{\circ} \mathrm{C}$ and step-down $\mathrm{RH}$ strategy ( $40 \%$ for $1,3,5,7 \mathrm{~h}$ and then continuous dehumidification). Also, the values of $\Delta E^{*}$ changed significantly (Table 3). The results indicate that the longer was the drying time, the more serious were the changes in redness and yellowness of Panax notoginseng roots. Drying at the temperature at $50^{\circ} \mathrm{C}, \mathrm{RH}$ of $40 \%$ for $3 \mathrm{~h}$ and then continuous dehumidification significantly improved the color parameters of final products.

Table 2 Rehydration ratio, shrinkage ratio and hardness of Panax notoginseng roots as affected by various drying conditions

\begin{tabular}{cccc}
\hline No. & RR/g. $\mathrm{g}^{-1}$ & Shrinkage ratio/\% & Hardness/g \\
\hline Fresh & 0 & 0 & 0 \\
1 & $1.86 \pm 0.02^{\mathrm{a}}$ & $0.66 \pm 0.06^{\mathrm{a}}$ & $529.93 \pm 11.05^{\mathrm{f}}$ \\
2 & $1.81 \pm 0.05^{\mathrm{a}}$ & $0.71 \pm 0.06^{\mathrm{a}}$ & $693.57 \pm 7.42^{\mathrm{c}}$ \\
3 & $1.61 \pm 0.01^{\mathrm{b}}$ & $0.72 \pm 0.10^{\mathrm{a}}$ & $916.29 \pm 6.97^{\mathrm{b}}$ \\
4 & $1.24 \pm 0.01^{\mathrm{c}}$ & $0.72 \pm 0.05^{\mathrm{a}}$ & $1442.18 \pm 35.21^{\mathrm{a}}$ \\
5 & $1.07 \pm 0.02^{\mathrm{d}}$ & $0.71 \pm 0.06^{\mathrm{a}}$ & $560.55 \pm 2.64^{\text {de }}$ \\
6 & $1.24 \pm 0.04^{\mathrm{c}}$ & $0.59 \pm 0.07^{\mathrm{a}}$ & $539.42 \pm 6.80^{\text {ef }}$ \\
7 & $1.28 \pm 0.04^{\mathrm{c}}$ & $0.15 \pm 0.10^{\mathrm{b}}$ & $493.08 \pm 7.87^{\text {gh }}$ \\
8 & $1.20 \pm 0.03^{\mathrm{c}}$ & $0.15 \pm 0.09^{\mathrm{b}}$ & $468.97 \pm 3.64^{\mathrm{hij}}$ \\
9 & $1.02 \pm 0.01^{\mathrm{d}}$ & $0.73 \pm 0.02^{\mathrm{a}}$ & $572.18 \pm 7.69^{\mathrm{d}}$ \\
10 & $1.19 \pm 0.01^{\mathrm{c}}$ & $0.61 \pm 0.07^{\mathrm{a}}$ & $553.92 \pm 6.05^{\mathrm{def}}$ \\
11 & $1.22 \pm 0.04^{\mathrm{c}}$ & $0.17 \pm 0.10^{\mathrm{b}}$ & $503.79 \pm 7.81^{\mathrm{g}}$ \\
12 & $1.18 \pm 0.03^{\mathrm{c}}$ & $0.15 \pm 0.09^{\mathrm{b}}$ & $478.63 \pm 4.54^{\text {ghi }}$ \\
13 & $1.83 \pm 0.06^{\mathrm{a}}$ & $0.16 \pm 0.06^{\mathrm{b}}$ & $459.00 \pm 10.42^{\mathrm{ij}}$ \\
14 & $1.65 \pm 0.04^{\mathrm{b}}$ & $0.15 \pm 0.07^{\mathrm{b}}$ & $484.45 \pm 3.97^{\text {ghi }}$ \\
15 & $1.56 \pm 0.05^{\mathrm{b}}$ & $0.14 \pm 0.04^{\mathrm{b}}$ & $481.91 \pm 3.38^{\text {ghi }}$ \\
\hline Note: :cdeghyj $^{\mathrm{b}}$ Different letters in the same column indicate significant differences
\end{tabular}
between samples $(p<0.05)$. RR represents the rehydration ratio.

Table 3 Color parameters $\left(L^{*}, a^{*}, b^{*}\right)$ and total color difference $\left(\Delta E^{*}\right)$ between raw and dried Panaxnotoginseng roots

\begin{tabular}{|c|c|c|c|c|}
\hline No. & $L^{*}$ & $a^{*}$ & $b^{*}$ & $\Delta E^{*}$ \\
\hline Fresh & $60.83 \pm 1.80^{\mathrm{a}}$ & $2.14 \pm 0.47^{\text {bc }}$ & $43.33 \pm 2.69^{\mathrm{a}}$ & 0 \\
\hline 1 & $55.64 \pm 2.20^{\mathrm{abc}}$ & $-0.12 \pm 1.25^{\mathrm{cd}}$ & $20.11 \pm 2.05^{\mathrm{bc}}$ & $23.91 \pm 0.46^{\mathrm{cd}}$ \\
\hline 2 & $50.25 \pm 5.55^{\mathrm{abc}}$ & $-0.21 \pm 1.15^{\mathrm{cd}}$ & $22.51 \pm 1.22^{\mathrm{b}}$ & $23.65 \pm 0.45^{\mathrm{d}}$ \\
\hline 3 & $45.51 \pm 4.42^{\mathrm{bc}}$ & $2.57 \pm 0.80^{\mathrm{b}}$ & $21.08 \pm 2.02^{\mathrm{bc}}$ & $27.08 \pm 0.93^{\mathrm{abcc}}$ \\
\hline 4 & $42.60 \pm 2.20^{\mathrm{c}}$ & $7.03 \pm 1.25^{\mathrm{a}}$ & $21.03 \pm 2.05^{\mathrm{bc}}$ & $29.23 \pm 0.37^{\mathrm{a}}$ \\
\hline 5 & $50.25 \pm 5.55^{\mathrm{abc}}$ & $-0.21 \pm 1.15^{\mathrm{cd}}$ & $22.51 \pm 1.22^{\mathrm{b}}$ & $23.65 \pm 0.45^{\mathrm{d}}$ \\
\hline 6 & $54.13 \pm 5.55^{\mathrm{abc}}$ & $-0.58 \pm 1.15^{\mathrm{d}}$ & $19.59 \pm 1.22^{\mathrm{bc}}$ & $24.99 \pm 0.31^{\mathrm{bcd}}$ \\
\hline 7 & $57.52 \pm 4.42^{\mathrm{ab}}$ & $-1.20 \pm 0.80^{\mathrm{d}}$ & $19.62 \pm 2.02^{\mathrm{bc}}$ & $24.25 \pm 0.25^{\mathrm{bcd}}$ \\
\hline 8 & $55.33 \pm 6.10^{\mathrm{abc}}$ & $-0.37 \pm 1.40^{\mathrm{cd}}$ & $19.66 \pm 3.57^{\mathrm{bc}}$ & $24.60 \pm 1.90^{\mathrm{bcd}}$ \\
\hline 9 & $45.67 \pm 8.11^{\mathrm{bc}}$ & $-0.04 \pm 0.52^{\mathrm{bcd}}$ & $22.51 \pm 1.06^{\mathrm{b}}$ & $26.20 \pm 2.36^{\mathrm{abcc}}$ \\
\hline 10 & $45.85 \pm 4.42^{\mathrm{bc}}$ & $-0.18 \pm 0.80^{\mathrm{cd}}$ & $19.89 \pm 2.02^{\mathrm{bc}}$ & $27.98 \pm 0.87^{\mathrm{ab}}$ \\
\hline 11 & $50.25 \pm 9.90^{\mathrm{abc}}$ & $-0.39 \pm 1.82^{\mathrm{cd}}$ & $20.99 \pm 3.13^{\mathrm{bc}}$ & $25.37 \pm 3.90^{\mathrm{bcd}}$ \\
\hline 12 & $48.77 \pm 8.11^{\mathrm{abc}}$ & $0.54 \pm 0.52^{\mathrm{bcd}}$ & $23.89 \pm 1.06^{\mathrm{b}}$ & $23.36 \pm 1.91^{\mathrm{d}}$ \\
\hline 13 & $53.78 \pm 7.19^{\mathrm{abc}}$ & $-0.10 \pm 1.54^{\mathrm{cd}}$ & $16.79 \pm 2.22^{\mathrm{c}}$ & $27.82 \pm 1.00^{\mathrm{ab}}$ \\
\hline 14 & $50.21 \pm 2.20^{\mathrm{abc}}$ & $0.55 \pm 1.25^{\mathrm{bcd}}$ & $18.99 \pm 2.05^{\mathrm{bc}}$ & $26.62 \pm 0.37^{\mathrm{abcc}}$ \\
\hline 15 & $48.65 \pm 4.42^{\mathrm{abc}}$ & $1.35 \pm 0.80^{\text {bcd }}$ & $18.64 \pm 2.02^{\mathrm{bc}}$ & $27.61 \pm 0.57^{\mathrm{abc}}$ \\
\hline
\end{tabular}

Note: ${ }^{\text {abcde }}$ : Different letters in the same column indicate significant differences between samples $(p<0.05) . L^{*}$ is the white-black value; $b^{*}$ is the yellow-blue value; $a^{*}$ is the red-green value; $\Delta E^{*}$ is the total color difference. 
The hardness value of dried Panax notoginseng roots significantly increased from 529.93 to 1442.18 as the drying temperature increased from $40^{\circ} \mathrm{C}$ to $70^{\circ} \mathrm{C}$ (Table 2). In fact, high drying temperature leads to severe drying intensity, which increases the surface hardness of materials. The hardness decreased at constant drying temperature of $50^{\circ} \mathrm{C}$ or $55^{\circ} \mathrm{C}$ as the relative humidity increased from $20 \%$ to $50 \%$. It is easy to understand that the evaporation of moisture on the material surface in high $\mathrm{RH}$ environments was slow, which had been reflected in the drying kinetics. In addition, there was no significant difference in hardness values between constant drying temperature at $50^{\circ} \mathrm{C}$ and relative humidity at $40 \%$ for different holding times at 3,5 and $7 \mathrm{~h}$, but they were significantly less than that at $1 \mathrm{~h}$. This demonstrated that the relative humidity control in the drying process directly affected the drying intensity and was closely related to the material hardness.

\subsection{Correlation between process parameters, quality attributes} of PanaxNotoginsengroots and energy usage

The correlation matrix between THC-HAD parameters, quality attributes of Panax notoginseng roots and energy usage is shown in Figure 8. It includes the following process parameters: 1) Drying temperature $D_{T},{ }^{\circ} \mathrm{C} ; 2$ ) Drying time $D_{t}, \mathrm{~h} ; 3$ ) Rehydration ratio (RR); 4) the content of Panax notoginseng saponins (PNS), \%; 5) $R_{1}$ is the content of ginsenoside $R_{1}, \%$; 6) $R_{g 1}$ is the content of ginsenoside $R_{g 1}, \%$; 7) $R_{e}$ is the content of ginsenoside $R_{e}, \%$; 8) $R_{d}$ is the content of ginsenoside $R_{d}, \%$; 9) $R_{b 1}$ is the content of ginsenoside $R_{b 1}, \%$; 10) specific energy consumption ( $\mathrm{Sec}), \mathrm{kW} \cdot \mathrm{h} / \mathrm{kg} ; 11$ ) heat accumulation (Ha), ${ }^{\circ} \mathrm{C} \cdot \mathrm{h}$; 12) shrinkage ratio $(\mathrm{Sr}), \%$; 13) lightness $L^{*}$; 14) yellowness $\left.b^{*} ; 15\right)$ redness $\left.a^{*} ; 16\right)$ total color difference $\left(\Delta E^{*}\right)$.

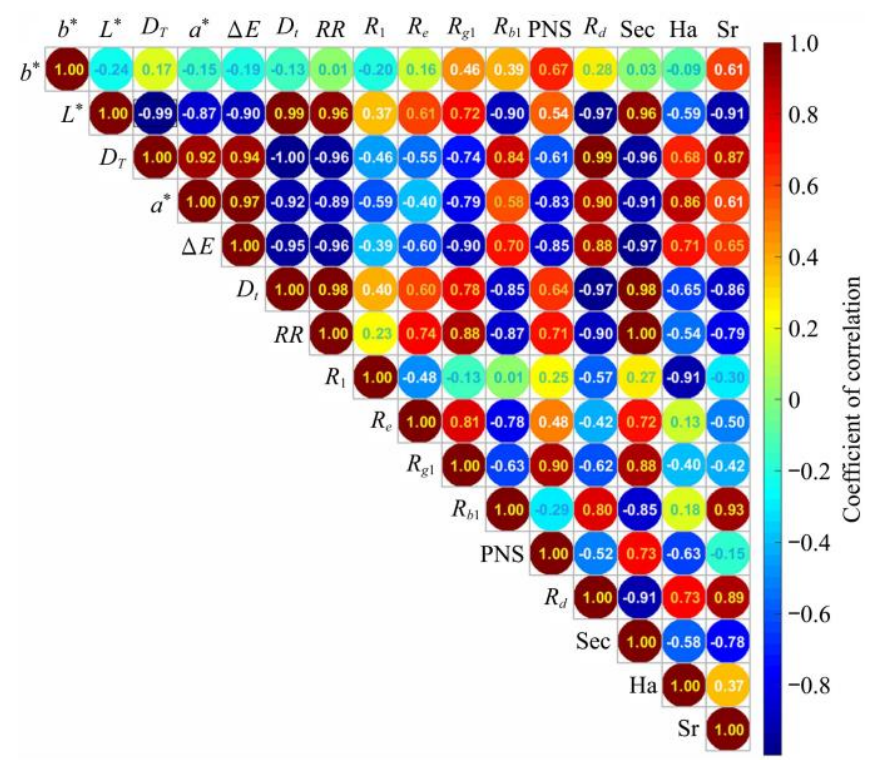

Note: $D_{T}$ is the drying temperature, ${ }^{\circ} \mathrm{C} ; D_{t}$ is the drying time, $\mathrm{h} ; R R$ represents the rehydration ratio; PNS represents the content of Panax notoginseng saponins, \%; $R_{1}$ is the content of ginsenoside $R_{1}, \% ; R_{g 1}$ is the content of ginsenoside $R_{g 1}, \% ; R_{e}$ is the content of ginsenoside $R_{e}, \% ; R_{d}$ is the content of ginsenoside $R_{d}, \% ; R_{b 1}$ is the content of ginsenoside $R_{b 1}, \%$; Sec represents the specific energy consumption, $\mathrm{kW} \cdot \mathrm{h} / \mathrm{kg}$; Ha represents the heat accumulation, ${ }^{\circ} \mathrm{C} \cdot \mathrm{h} ; \mathrm{Sr}$ represents the shrinkage ratio, $\% ; L^{*}$ is the white-black value; $b^{*}$ is the yellow-blue value; $a^{*}$ is the red-green value; $\Delta E^{*}$ is the total color difference.

Figure 9 Correlation matrix between THC-HAD parameters, quality attributes of Panax notoginseng roots and energy usage

The results indicate that the values of $L^{*}$ parameter were negatively correlated $(p<0.05)$ with $D_{T}(r=-0.99), R_{b 1}(r=-0.90), R_{d}$ $(r=-0.97)$ and $S r(r=-0.91)$, while positively correlated with $D_{t}$ $(r=0.99)$, RR ( $r=0.96)$. Additionally, the values of $a^{*}$ parameter were negatively correlated $(p<0.05)$ with $D_{t}(r=-0.92)$ and RR ( $r=-0.89)$, while positively correlated with $D_{T}(r=0.92)$ and $R_{d}$ $(r=0.99)$. This indicated that the long drying time was not conducive to the formation of good color value, and indirectly proved that the color can reflect the content of $R_{d}$. The values of index $\Delta E^{*}$ were negatively correlated with $D_{t}(r=-0.87)$ and $D_{T}$ $(r=-0.93)$. This was consistent with the fact that high drying temperature and long drying time seriously damage the color of materials. The values of RR were negatively correlated with $D_{T}$ $(r=-0.92)$. This was the same as the high drying temperature in the previous studies ${ }^{[22]}$, which led to severe drying intensity and serious damage to the structure of the material, which was not conducive to the rehydration to restore the original state. The content of PNS was negatively correlated with $D_{t}(r=-0.91)$ and $D_{T}$ ( $r=-0.95)$. Also, the content of $R_{g 1}$ was negatively correlated with $D_{t} \quad(r=-0.94)$ and $D_{T} \quad(r=-0.90)$. Quality (saponin content) correlation analysis showed that high drying temperature or long drying time, that is, essentially more heat accumulation, would lead to the decrease of saponin content. Additionally, SEC was negatively correlated with $D_{T}(r=-0.88)$ and positively correlated with $D_{t}(r=0.91)$. In fact, the energy consumption was mainly related to the drying time. In this study, the drying time of Panax notoginseng roots under high drying temperature $\left(70^{\circ} \mathrm{C}\right)$ was so long, resulting in a significant negative correlation between the drying temperature and energy consumption.

Generally speaking, the drying time of drying temperature at $50^{\circ} \mathrm{C}$ is shorter than that at other temperatures $\left(40^{\circ} \mathrm{C}\right.$ and $\left.70^{\circ} \mathrm{C}\right)$, the material surface does not harden and crusts significantly, and the drying time under the constant $\mathrm{RH}$ of $40 \%$ for $3 \mathrm{~h}$ and then step-down RH from $40 \%$ to $8 \%$ condition is significantly shortened and the energy consumption is reduced compared with other $\mathrm{RH}$ control strategies. Therefore, the drying temperature of $50^{\circ} \mathrm{C}$, constant RH of $40 \%$ for $3 \mathrm{~h}$ and then step-down RH from $40 \%$ to $8 \%$ should be as the appropriate drying process conditions.

\section{Conclusions}

Step-down relative humidity $(\mathrm{RH})$ convective hot air drying of whole Panax notoginseng roots was experimentally investigated. The aims of this study were to evaluate the effects of temperature and humidity controlled hot air drying (THC-HAD) on the drying characteristics of whole Panax notoginseng roots, quality parameters and specific energy consumption. The drying time was significantly affected by the drying temperature followed by the relative humidity $(\mathrm{RH})$ of the drying air. Drying at the temperature from $40^{\circ} \mathrm{C}$ to $70^{\circ} \mathrm{C}$ under continuous dehumidification from $25 \%$ to $8 \%$ took 34.5 to $98.0 \mathrm{~h}$. Drying at the temperature of $50^{\circ} \mathrm{C}, \mathrm{RH}$ of $40 \%$ for $3 \mathrm{~h}$ and then continuous dehumidification from $40 \%$ to $8 \%$ allowed to shorten the drying time by $25 \%$ compared to drying at the same temperature and continuous dehumidification. The energy consumption was related to the drying time. Compared to the continuous dehumidification strategy, the step-down $\mathrm{RH}$ strategy allowed to save $39.4 \%$ energy. The quality evaluation revealed that drying temperature, $\mathrm{RH}$, and step-down $\mathrm{RH}$ had significant effects on the shrinkage, rehydration ratio, color, and ginsenosides content of dried roots. The results provide evidence that the step-down RH strategy contributed to the formation of a porous structure, enhancement of drying efficiency and improvement of quality attributes. Based on the evaluation of the drying time, energy consumption and quality attributes, drying at the temperature of $50^{\circ} \mathrm{C}$, constant $\mathrm{RH}$ of $40 \%$ for $3 \mathrm{~h}$ and then step-down RH from $40 \%$ to $8 \%$ was found to be the most favorable 
combination of drying conditions for dehydration of Panax notoginseng roots. The results will be useful for manufacturers of dryers, dried Panax notoginseng roots, as well as pharmaceuticals and medicines made from Panax notoginseng roots.

\section{Acknowledgements}

This work was supported in part by the Hebei Province Key Research and Development Project (Grant No. 203777119D, 19227210D), in part by the Scientific Research Projects of Universities in Hebei Province (Grant No.ZD2021056), in part by the Hebei Province College and Middle School Students Science and Technology Innovation Ability Cultivation Project (Grant No. 2021H060505) and part by China Agriculture Research System of MOF and MARA (CARS-21). The author would like to thank Master candidate Sara Zielinska and Associate Professor Congcong Li for their help in this study.

\section{[References]}

[1] Bai T Y. Medium and short wave infrared drying characteristics and quality of Panax notoginseng. Master dissertation.Beijing: China Agricultural University, 2019; 81p. (in Chinese)W

[2] Han L F, Sakah K J, Liu L L, Kojo A, Wang T, Zhang Y. Saponins from roots of Panax notoginseng. Chinese Herbal Medicines, 2014; 6(2): 159-163.

[3] Zhang X, Qi L, Liu D. Pharmacological effects of Panax notoginseng and its active constituents. J. Med. Res., 2007; 36(4): 96-98.

[4] Guo Q L, Li P Y, Wang Z, Cheng Y K, Wu H C, Yang B, et al. Brain distribution pharmacokinetics and integrated pharmacokinetics of Panax notoginsenoside $\mathrm{R} 1$, Ginsenosides $\mathrm{Rg} 1, \mathrm{Rb} 1, \mathrm{Re}$ and $\mathrm{Rd}$ in rats after intranasal administration of Panax notoginseng saponins assessed by UPLC/MS/MS. Journal of Chromatogrphy B, 2014; 969: 264-271.

[5] Davidson V J, Martynenko A I, Parhar N K, Sidahmed M, Brown R B. Forced-air drying of ginseng root: Pilot-scale control system for three-stage process. Drying Technology,2009; 27(3): 451-458.

[6] Gao M J, Feng G Q, Zeng H C, Zhao A, Ma N. Study on the processing method of Panax notoginseng producing area. Lishizhen Medicine and Materia Medica Resarch, 2011; 22(1):198-199. (in Chinese)

[7] Karabulut I, Topcu A, Duran A, Turan S, Ozturk B. Effect of hot air drying and sun drying on color values and $\beta$-carotene content of apricot (Prunus armenica L.). LWT-Food Science and Technology, 2007; 40(5): 753-758.

[8] Guo H. Research on drying characteristics and mass transfer model of Yunnan Panax notoginseng. Master dissertation. Kunming: Kunming University of Science And Technology, 2015; 75p. (in Chinese)

[9] Xiao H W, Bai J W, Xie L, Sun D W, Gao Z J. Thin-layer air impingemen drying enhances drying rate of American ginseng (Panax quinquefolium L.) slices with quality attributes considered. Food and Bioproducts Processing, 2015; 94: 581-591.

[10] Zhao H Y. Hot air drying characteristics and quelity of American ginseng based on being controlled temperature and humidity. Master dissertation. Beijing: China Agricultural University, 2016; 99p. (in Chinese)

[11] Ju H Y, Zhao S H, Mujumdar A S, Zhao H Y, Duan X, Zheng Z A, et al Step-down relative humidity convective air drying strategy to enhance drying kinetics, efficiency, and quality of American ginseng root (Panax quinquefolium). Drying Technology, 2019; 38(7): 903-916.

[12] Gulati T, Datta A K. Mechanistic understanding of case-hardening and texture development during drying of food materials. Journal of Food Engineering, 2015; 166: 119-138.

[13] Du X W, Wills R B H, Stuart D L. Changes in neutral and malony ginsenosides in American ginseng (Panax quinquefolium) during drying, storage and ethanolic extraction. Food Chemistry, 2004; 86(2): 155-159.

[14] Dai J W, Rao J Q, Wang D, Xie L, Xiao H W, Liu Y H, et al. Process-based drying temperature and humidity integration control enhances drying kinetics of apricot halves. Drying Technology, 2015; 33(3): 365-376.

[15] Ju H Y, El-Mashad H M, Fang X M, Pan Z L, Xiao H W, Liu Y H, et al Drying characteristics and modeling of yam slices under different relative humidity conditions. Drying Technology, 2016; 34(3): 296-306.
[16] Ju H Y, Xiao H W, Zheng X, Guo X L, Liu Y H, Zhang W P, et al. Effect of hot air relative humidity on drying characteristics of carrot slabs. Transactions of the CSAE, 2015; 31(16): 296-304. (in Chinese)

[17] National Pharmacopoeia Committee. Pharmacopoeia of People's Republic of China Part 1. Beijing: Chemical Industry Press, 2015; 2572p.

[18] Wang J, Fang X M, Mujumdar A S, Qian J Y, Zhang Q, Yang X H, et al Effect of high-humidity hot air impingement blanching (HHAIB) on drying and quality of red pepper (Capsicum Annuum L.). Food Chemistry, 2017; 220: 145-152.

[19] Pathare P B, Opara U L, Al-Said A J. Colour measurement and analysis in fresh and processed foods: A review. Food and Bioprocess Technology, 2013; 6: 36-60.

[20] Xiao H W, Gao Z J. The application of scanning electron microscope (SEM) to study the microstructure changes in the field of agricultural products drying. In: Scanning Electron Microscopy. Kazmiruk V (Ed.). Rijeka, Croatia: IntechOpen, 2012; pp.213-226.

[21] Qu C, Bai Y, Jin X, Wang Y, Zhang K, You J Y, et al. Study on ginsenosides in different parts and ages of Panax quinquefolius L. Food Chemistry, 2009; 115(1): 340-346.

[22] Chen J K, Lin H T, Lin Y F, Li H, Wang Z Y. Optimized technology of Pleurotus eryngii by microwave-vacuum drying based on quality and energy consumption. Transactions of the CSAE, 2014; 30(3): 277-284. (in Chinese)

[23] Jiang D L, Xiao H W, Zielinska M, Zhu G F, Bai T Y, Zheng Z A. Effect of pulsed vacuum drying on drying kinetics and quality of roots of Panax notoginseng (Burk.) F. H. Chen (Araliaceae). Drying Technology, 2021; 39(16): 2234-2251

[24] Aral S, BeşeA V. Convective drying of hawthorn fruit (Crataegus spp.): Effect of experimental parameters on drying kinetics, color, shrinkage, and rehydration capacity. Food Chemistry, 2016; 210: 577-584.

[25] Horuz E, Bozkurt H, Karataş H, Maskan M. Effects of hybrid (microwave-convectional) and convectional drying on drying kinetics, total phenolics, antioxidant capacity, vitamin $\mathrm{C}$, color and rehydration capacity of sour cherries. Food Chemistry, 2017; 230: 295-305.

[26] Brito R C D, Padua T F D, Freire J T, Bettega R. Effect of mechanical energy on the energy efficiency of spouted beds applied on drying of sorghum [Sorghum bicolor (L) moench]. Chemical Engineering and Processing: Process Intensification, 2017; 117: 95-105.

[27] Zhang Y, Zhu G F, Li X Y, Zhao Y, Lei D W, Ding G Q, et al. Combined medium- and short-wave infrared and hot air impingement drying of sponge gourd (Luffa cylindrical) slices. Journal of Food Engineering, 2020; 284: 110043. doi: 10.1016/j.jfoodeng.2020.110043.

[28] Ju H Y. The design and experiment of hot air drying technology based on being controlled temperature and humidity Doctoral dissertation. Beijing: China Agricultural University, 2016; 91p.

[29] Dev S R S, Geetha P, Orsat V, Gariépy Y, Raghavan G S V. Effects of microwave-assisted hot air drying and conventional hot air drying on the drying kinetics, color, rehydration, and volatiles of Moringa oleifera. Drying Technology, 2011; 29(12): 1452-1458.

[30] Yadollahinia A, Jahangiri M. Shrinkage of potato slice during drying. Journal of Food Engineering, 2009; 94(1): 52-58.

[31] Li X Y, Liu Y H, Gao Z J, Xie Y K, Wang H. Computer vision online measurement of shiitake mushroom (Lentinus edodes) surface wrinkling and shrinkage during hot air drying with humidity control. Journal of Food Engineering, 2021; 292: 110253. doi: 10.1016/j.jfoodeng.2020.110253.

[32] Sasongko S B, Hadiyanto H, Djaeni M, Perdanianti A M, Utari F D Effects of drying temperature and relative humidity on the quality of dried onion slice. Heliyon, 2020; 6(7): e04338. doi: 10.1016/j.heliyon.2020. e04338.

[33] Liu X, Qiu Z, Wang L, Chen Y. Quality evaluation of Panax notoginseng extract dried by different drying methods. Food and Bioproducts Processing, 2011; 89(1): 10-14.

[34] Du X W, Zhou J, Li B, Zhao G A, Bai T Z. Analysis of ginsenosides and carbohydrates in steaming products of American ginseng. Acta Pharmaceutica Sinica B, 2005; 33(2): 137-141. (in Chinese)

[35] Zhou J. Systematic studies on quality standard and processing method of American ginseng. Master dissertation. Harbin: Heilongjiang University of Chinese Medicine, 2005; 95p. (in Chinese)

[36] Ge F, Huang Z J, Yu H, Wang Y, Liu D Q. Transformation of Panax notoginseng saponins by steaming and Trichoderma longibrachiatum. Biotechnology \& Biotechnological Equipment, 2016; 30(1): 165-172. 